\title{
The Role of Academic Accreditation in Guiding Saudi Universities to Respond to the Fourth Industrial Revolution Receivables
}

\author{
Omar Ali Refaiah \\ Assistant Professor in the Department of Educational Administration and Planning \\ Quality and Academic Accreditation Advisor \\ College of Education / Imam Muhammad bin Saud Islamic University \\ omarrfa@gmail.com
}

Received:23/6/2020

Accepted:26/7/2020

\begin{abstract}
:
The current study aims to identify the academic accreditation role in directing the Saudi universities to respond to 4thInternational Revolution Receivables. This study is based on the mixed method (quantitative and qualitative), and two tools are used to collect data: questionnaire, and interview. The questionnaire is designed to have 20 paragraphs distributed into four aspects. After approving the questionnaire reliability and credibility, it was distributed on a sample of (170) faculty members working in the scope of quality and academic accreditation in governmental universities at Riyadh city for the academic year of (201912020). The study results show a clear identification of the Fourth Industrial Revolution Receivables in the higher education domain. The results also show the adequacy of accreditation standards in their theoretical dimension, but in practice the reality of universities are in need of more attention. The qualitative results had valuable additions, in clarifying the reasons for the gap between theory and practice related to academic accreditation standards. As well as clarifying the constraints reducing the effectiveness of this role. In light of the mixed results, the study set particular recommendations that aim to increase the role of the academic accreditation in directing Saudi universities to respond to the 4thInternational Revolution Receivables
\end{abstract}

Keywords: Academic Accreditation, $4^{\text {th }}$ International Revolution Receivables, Labor Market Needs, Learning Outcomes, Graduate Alignment, Quality in Higher Education. 


\title{
دور الاعتماد الأكاديميّ في توجيه الجامعات السعوديّة للاستجابة لاستحقاقات الثورة الصناعيّة الرابعة
}

\author{
عمر علي الرفايعه

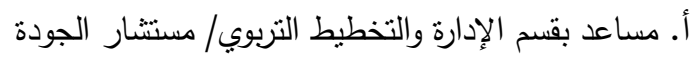 \\ والاعتماد الأكاديميّ الإنيط \\ كليّة التربية/ جامعة الإمام محمد بن سعود الإسلاميّة \\ omarrfa@gmail.com
}

قبول البحث 2020/7/26

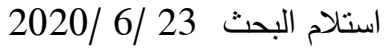

| (لملخص:

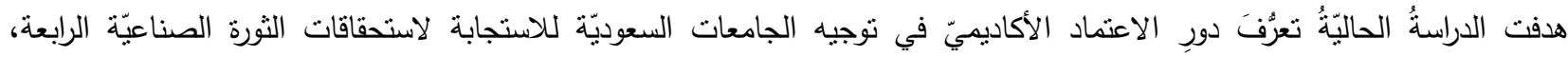

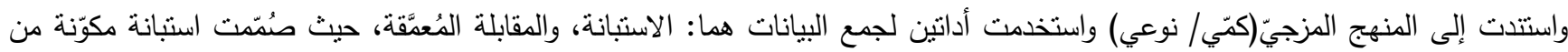
20 فقرة موزّعة على أربعة أبعاد، وبعد إجراءات التحقق من صِدقها وثباتها وُزّعت على عيّنة مكوّنة من 170 عضواً من أعضاء هيئة التدريس العاملين في الجودة والاعتماد الأكاديميّ، ووحداتها في الجامعات الحكوميّة في مدينة الرياض للعام الدراسيّ 2020/2019م، ومن التيّة نتائج الدراسة

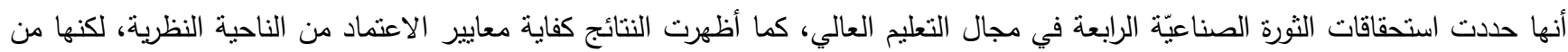

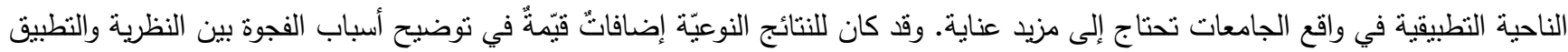

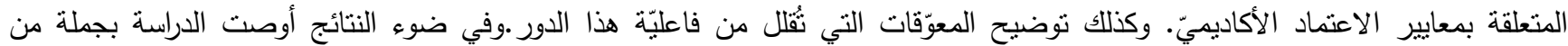
التوصيات لزيادة الدور الذي يقوم به الاعتماد الأكاديميّ في توجيه الجامعات السعوديّة للاستجابة لاستحقاقات الثورة الصناعيّة الرابعة. الكلمات المفتاحية: الحوكمة، أبعاد الحوكمة، الأداء المتميز .

التعليم العالي؛ ثُ عُدًلت جهة الإثراف في نفس السنة لتصبح الهيئة المقدمة

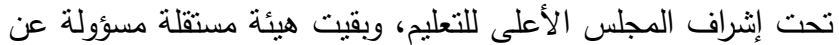

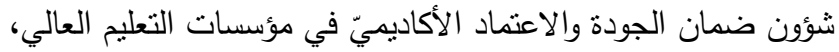
بغرض الارتقاء بجودته، وضمان الوضوح والثفافية في تقييم مخرجاته

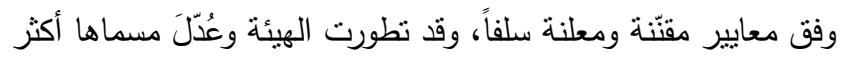

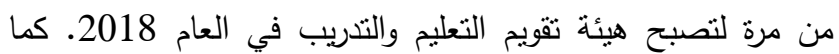

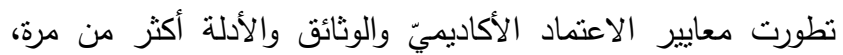

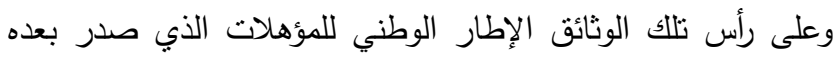

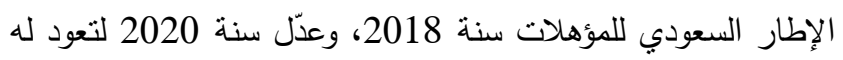
التسمية القيمة "الإطار الوطني للمؤهلات"، وكل هذه التعديلات ناتجة عن مراجعات عميقة أثنركت الهيئة فيها الجامعات والخبراء في الخهاء الميدان الأكاديميّ. ومن المناسب بيانه هنا أن الحديث عن مواءمة التعليم العالي السعودي لمنطلبات سوق العمل لم تكن قضية مطروحة

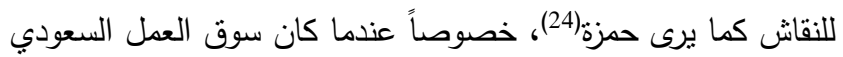
يسنوعب جميع خرّيجي مؤسسات التعليم العالي ويضمن لهم الوظيفة

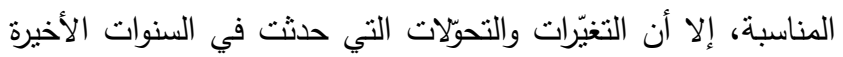
في المجالات الاقتصادية وأسواق العمل في المملكة جعلت مثل هذه المواءمة قضية جوهريّة، وضرورة لا بد منها.

لقد كان للتحوّل في التعليم من الهنحى القائم على الأهداف إلى الى

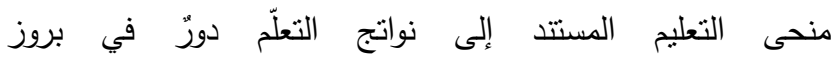
الاعتمادالأكاديميّ على مستوى العالم، وقد بدأ ذاك التحوّل في أمريكا استجابة لضغوط دافعي الضرائب ومطالباتهم بإصلاح التعليم الذي التي تدنّت نتائجه لدى أبنائهم، فجاءت نواتج التعلم وإعلانها كمحك تحتكم

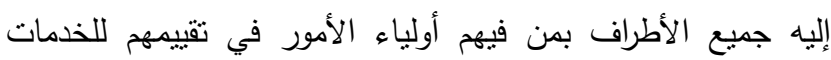

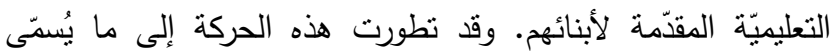
الاعتماد الأكاديميّ، حيث انتشر بعد ذلك في العالم. ولقد شَهِهَ العقدان

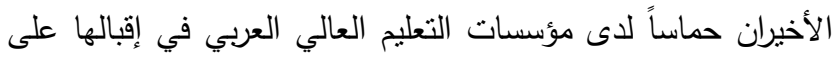

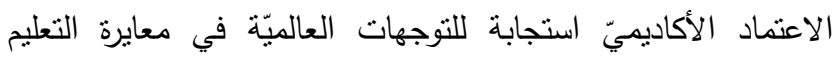

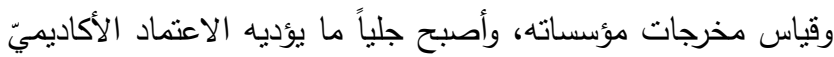
من دورٍ قتمٍٍ يتمتّلُ في حماية حق المجتمع في مخرجات تعليم ذات جودة عالية من خلال تطبيق المعايير التي نُعلنها هيئاته سلفاً للمؤسسات التعليمية وللمجتمع (32). لقد اهتمت المملكة العربية السعوديّة بالاعتماد الأكاديميّ ولميّي لجامعاتها والبرامج المقّمة فيها، فأنثأت الهيئة الوطنية للتقويم والاعتماد الأكاديميّ في العام 2004/2003تحت إثراف مجلس 
للحاجات المستجدة،ولعل هذا أخطر التحديات التي نواجه الجامعات

جاءت الحاجة إلى هيئات الاعتماد ومعاييرها، لتتوب عن الدول

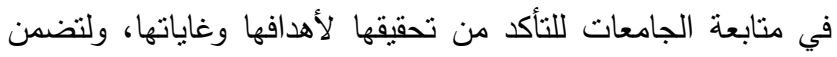
الدولة الواحدة أن كل جامعاتها تسير في نفس الاتجاه وتسعى لنفس الدرجة من جودة المخرجات، من هنا جاءت أهيّة الاعتماد

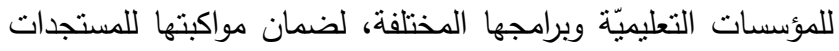
المختلفة والمتسارعة، ولعل من أخطرها اليوم ما تفرضه الثونة الثرة الصناعيّة الرابعة من استحقاقات متعلقّة بطبيعة الوظائف والمهن وخصائص شاغليها، والمعارف والمهارات التي يجب أن يتسلّحوا بها. ومنذ إطلاق مصطلح الثورة الصناعيّة الرابعة في المنتدى الاقتصادي

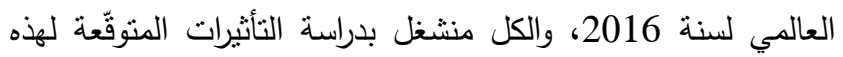
الثورة، وما سيترتب على زيادة التقارب فيها بين العوالم الماديّة والرقميّة والبيولوجية، وما الذي على الإنسان أن يفعله ليؤثر في مجرياتها، لترشيد تأثيراتها في حياته وعلاقاته مع البيئات النقافية والاقتصاديّة

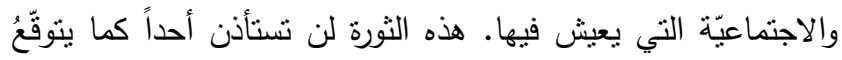

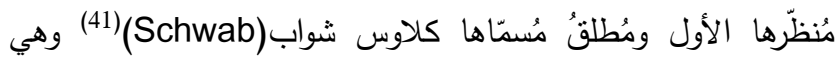

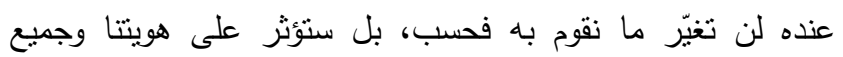
القضايا المرنبطة بها من مثل إحساسنا بالخصوصيّة، ومفاهيمنا للملكيّة، وأنماط استهلاكنا، والوقت الذي نكرّسهُ للعمل والترفيه، وكيف بلفي

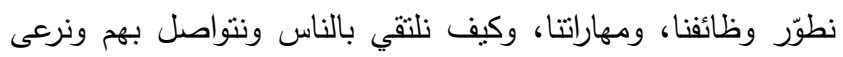
علاقاتتا معهم، هذه التأثيرات كلها تحتاج إلى استعداد وتصدً: والآمال معلّقة في هذا الثأن على النظم النعليميّة للقيام بحركة النزشيد والتكيّف.

تسعى الثورة الصناعيّة الرابعة إلى تحقيق الترابط التفاعليّ بين تكنولوجيا المعلومات والآلات والإنسان، بهدف إيجاد كفاءة عالية في لئي استخدام الموارد للتصنيع الذكيّ، ومع زيادة وضوح هذا الترابط زادت التساؤلات حول اتجاهات التعليم المستقبليّة لتحقيق التتمية المستدامة

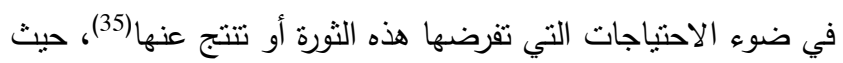

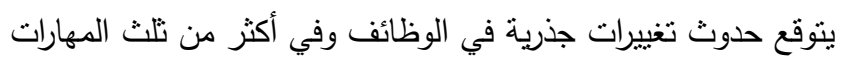
المهمّة الموجودة حالياً لدى القوى العاملة، الأمر الذي باتت الحاجة الدانية معه ملحَة لإعادة النظر في المناهج وطرق التدريس لضمان نواتج

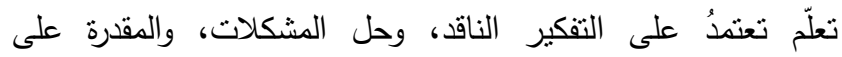
التواصل الفاعل، والعمل الفريقي. وتزداد مهيّة الجامعات تحديداً في

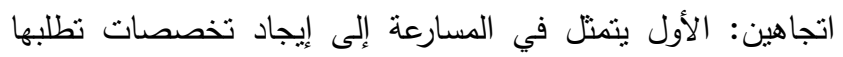

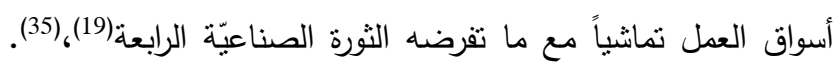

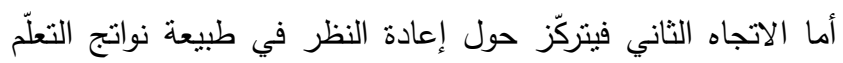

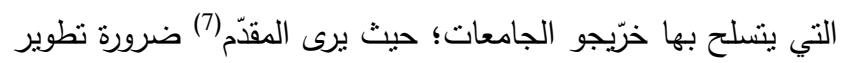

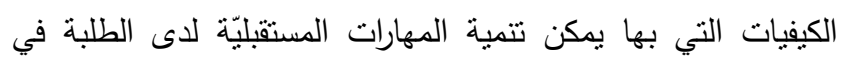

صحيُّ أن للاعتماد الأكاديميّ فوائدَ كثيرةً كرفع سُمعة الجامعة،

وتعزيز البُعد المهنيّ في تطوير أداء أعضاء هيئة التدريس، لكن الأهم فيما تلمسه المجتمعات من الاعتماد إنما هو ضمان نوعيّة الخريجين

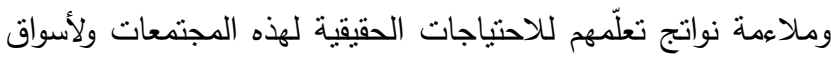
العمل فيها، وعلى هذا الأساس ترتفع نقة المجتمع بالجامعة، وتتال

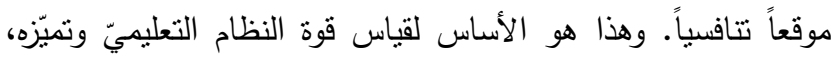

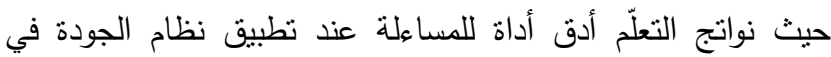

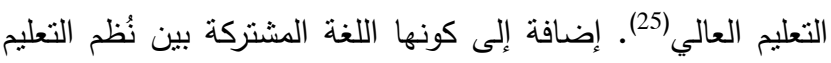

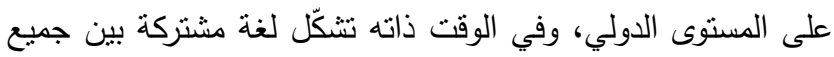

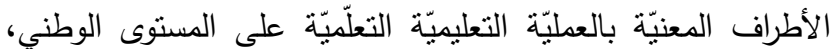
سواءً كانوا أكاديميين أم أرباب عمل أم طلبة.

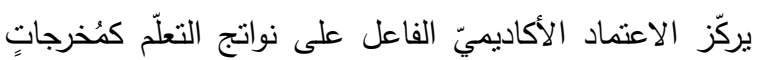

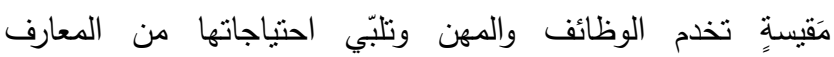
والمهارات، ولعل مما يؤكد على أهمية نواتج التعلم اليوم كمحور تدور

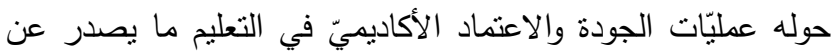
المنظمات الدوليّة من مثلك: منظمة التعاون الاقتصادي والتتمية

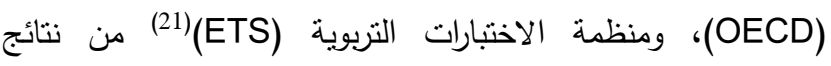
وتقارير، وما يرافق ذلك من مراجعات وقرارات. ولقد كان للاختبارات

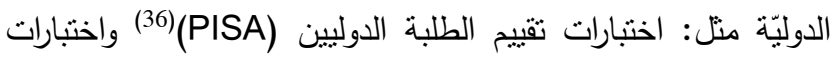
تقييم نواتج التعلّم في التعليم العالي(AHELO) (1) دور كبير في إذكاء التتافس بين الدول على إصلاح التعليم العام والتعليم العالي استتاداً

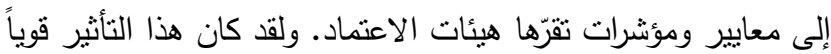
إلى درجة أن نتائج تقارير عام 2010 أدت إلى تعديل السياسات

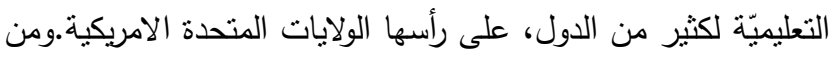

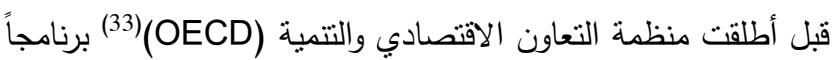

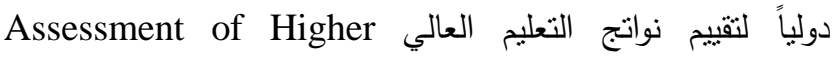
Education Learning (Outcomes (Ahelo) هدفت دراسةَ ما إذا كان من الممكن وضع تدابير دوليّة لتقييم نواتج

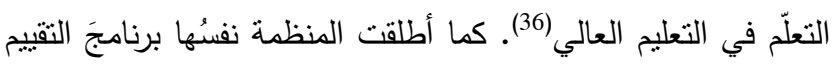

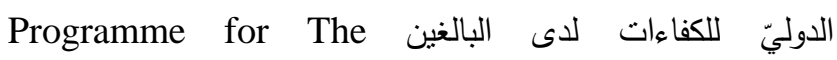
International Assessment of Adult Competencies (PIAAC)، وكان غرضه التأكد من درجة كفاءة الخرّيجين للمشاركة

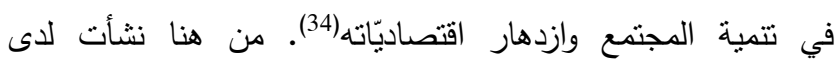
الجامعات المتقدمة قناعات بضرورة السعي الحثيث للتكيّف مع لهات منطلبات كل مرحلة واستحقاقاتها، من ذلك ما أكد عليه رئيس مجلس بأس جامعات أونتاريو Council of Ontario Universities كما عند بلوو (13) من أن العصر يتسم بالتغيّر المستمر، مما يتطلب مزيداً من

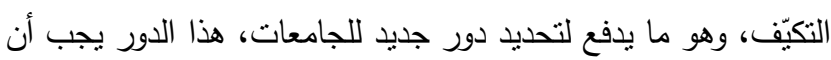

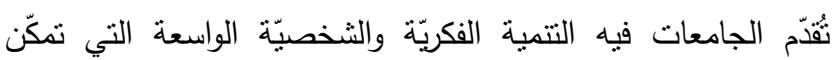
الخرّيجين من الازدهار في عالم يتغيّر باستمرار لضمان ملاءمتهم لفانه 
التساؤل الرئيس لهذه الدراسة هو "ما دور الاعتماد الأكاديميّ

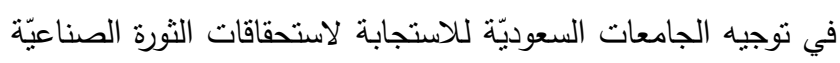
الرابعة؟ يتفرع من هذا التساؤل الأسئلة الفرعيّة الآتية: 1. ما استحقاقات الثثرة الصناعيّة الرابعة في مجال التعليم التئية

$$
\text { العالي؟ }
$$

2. ما درجة إسهام الاعتماد الأكاديميّ في نتجيه الجامعات

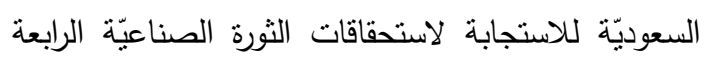

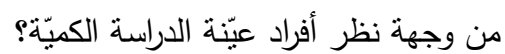

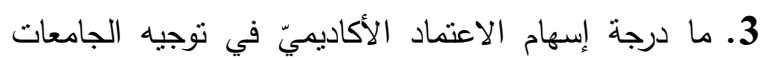
السعوديّة للاستجابة لاستحقاقات الثورة الصناعيّة الرابعة

$$
\text { من وجهة نظر الخبراء؟ }
$$

4. كيف يمكن لنتائج الدراسة النوعيّة أن تقدّم توضيحاً أكثر

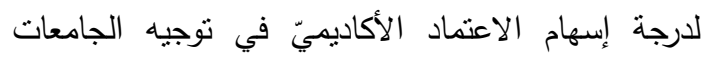

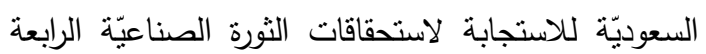

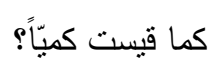

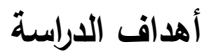

1. تحديد استحقاقات الثورة الصناعيّة الرابعة في مجال التعليم

$$
\text { العالي. }
$$

2. تحديد درجة إسهام الاعتماد الأكاديميّ في نتوجيه الجامعات السعوديّة للاستجابة لاستحقاقات الثورة الصناعيّة الرابعة الإدية من وجهة نظر أفراد عيّنة الدراسة الكيّة.

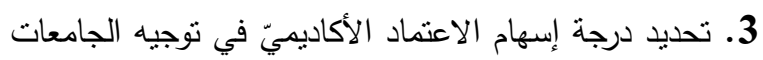
السعوديّة للاستجابة لاستحقاقات الثورة الصناعيّة الرابعة

$$
\text { من وجهة نظر الخبراء. }
$$

4. الاستفادة من البيانات النوعيّة في الوصول إلى تفسيرات

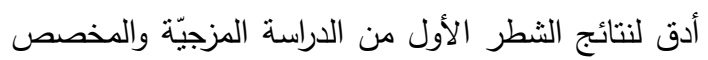

$$
\text { للاراسة الكمّية. }
$$

5. ثقديم نوصيات مستتدة إلى نتائج الدراسة لتستفيد منها الجهات المعنيّة في تطوير نطبيقات الجودة والاعتماد

$$
\text { الأكاديميّ في الجامعات السعوديّة. }
$$

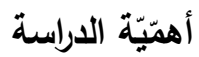

تتبع أهمية الدراسة من أهمّيّة الدور الهنوط بالاعتماد الأكاديميّ

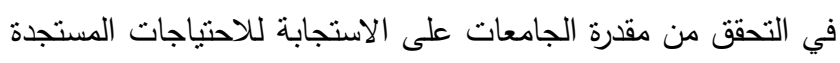

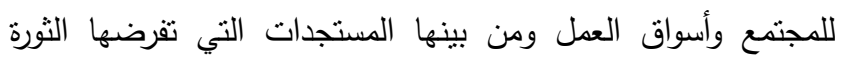

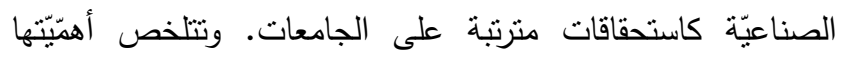
النظرية في التالي:

1. إضافتها للمعرفة العربية ما يتعلق باستحقاقات الثورة

$$
\text { الصناعيّة الرابعة في مجال التعليم العالي. }
$$

مختلف مراحلهم الدراسيّة، وفق أنظمة تعليميّة تسعى لتحقيق نتائج نوعيّة قابلة للقياس. في ضوء ما تقدّم واستتاداً إلى الدراسات التي نتاولت واقع

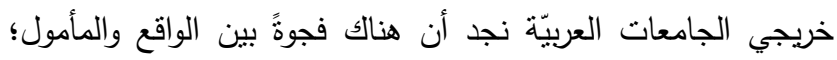

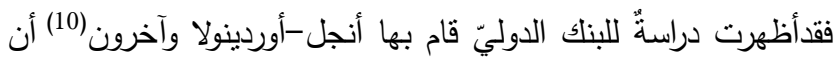
البلدان العربية، وبلدان حوض البحر الأبيض المتوسط نعاني من تدني فلاني

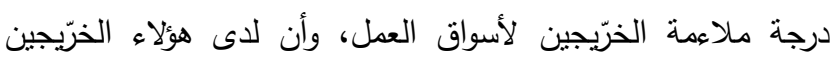

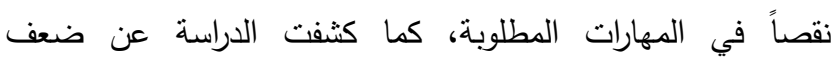

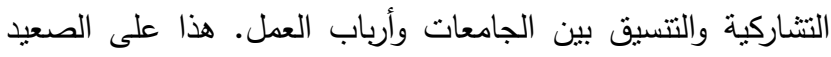

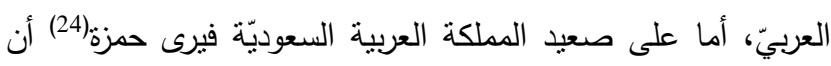
هناك ضعفاً في المواعهة بين مخرجات التعليم العالي واحتياجات النتمية الوطنيّة في المملكة، مع ندني التحصيل المعرفيّ والتأهيل

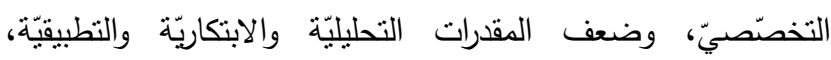
وقصور في تعزيز القيم والاتجاهات الإنتاجية. إضافة إلى تخريّج أعداد من الخرّيجين في تخصصات لا تحتاجها أسواق العمل، يوازيه نقص في تخصصات أخرى، وهذه النتائج تثير إلى طبيعة التواصل بين الجامعات وأرباب العمل، وضعف التشاركيّة في التخطيط لنواتج التعلّم التي ينسلح بها الخرّيجون.

مشكنة الاراسة

مع اهتمام المملكة بتطوير التعليم العالي وزيادة الاهتمام بمعايرته وتقويمه، وارتفاع وتيرة المناداة بضرورة الاستعداد للمستقبل

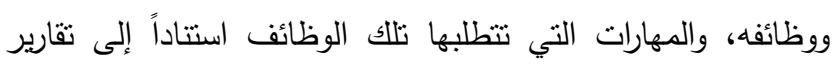

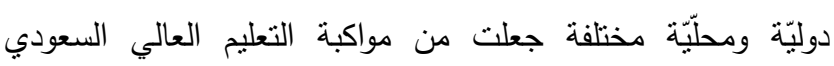

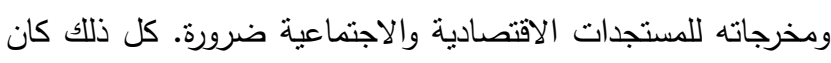

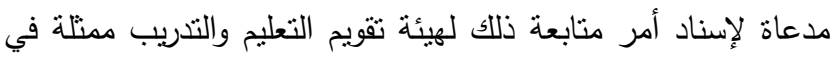

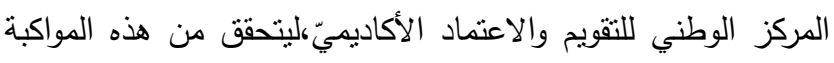

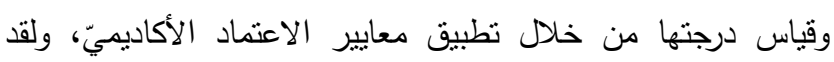

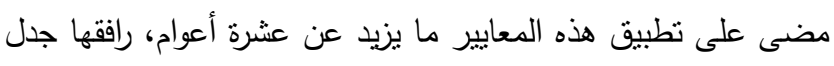

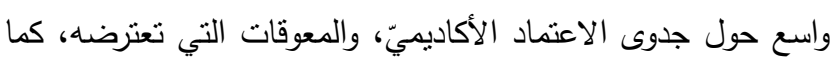

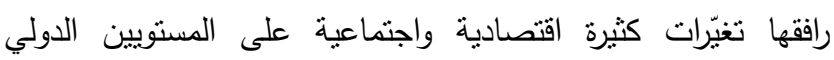

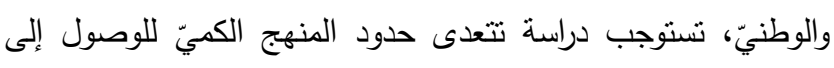

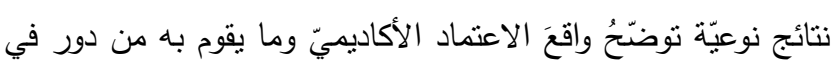

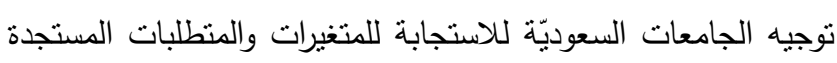

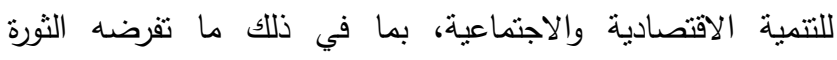

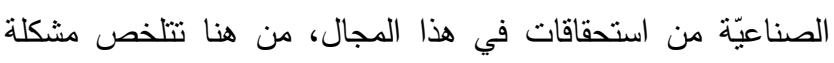

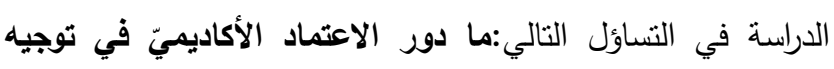

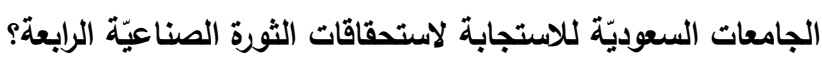
أسئلة الدراسة 
الحدود البشرية: اقتصر نطبيق أداة الدراسة الأولى (الاسنبانة) على

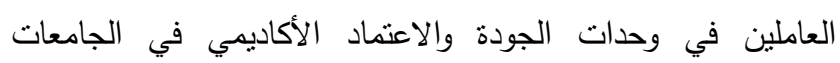
المستهدفة. في حين اقتصر تطبيق أداة الدراسة الثانية (بطاقة الدقابلة المعمّة) على المستشارين والخبراء في مجال الاعتماد الأكاديميّ،

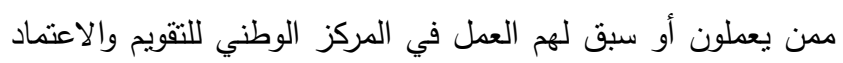

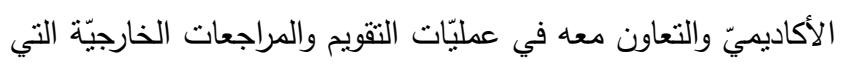
تستهدف جميع الجامعات السعوديّة. الحدود المكانية: طبقت أداتا الدراسة على الجامعات السعوديّة

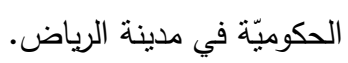

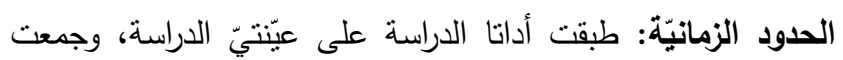

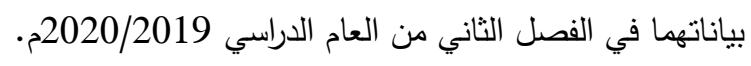

الإطار النظري والدراسات السابقة ينتاول هذا الفصل كلاً من الإطار النظري المتعلق بالثورة

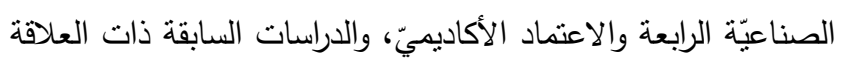
وفق البيان النالي:

\section{الثورة الصناعيّة الرابعة}

تُعرف الثورة الصناعيّة الرابعة بالاختصار الإنجليزي(IR4)،

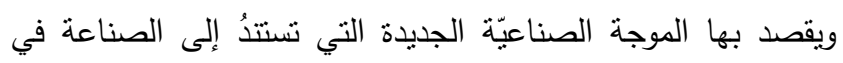

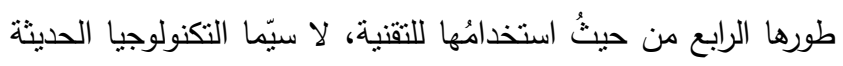
في مجالات الروبوتات والذكاء الاصطناعي، والطباعة الثلاثيّة الأبعاد، وإنترنت الأشياء، واستخدام التكنولوجيا في الحياة اليوميّة(26).

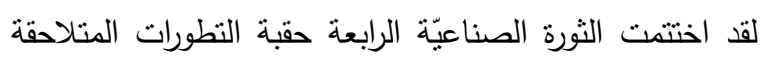

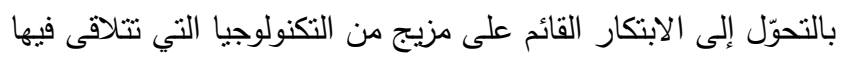

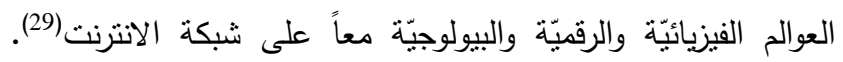

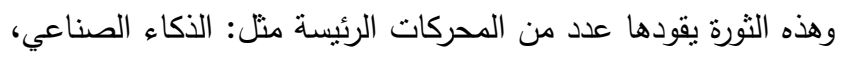

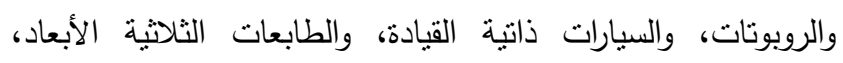

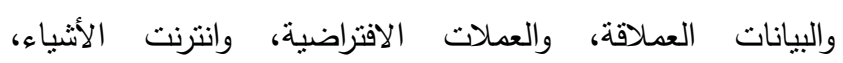
والبيوتكنولوجي، وتخزين الطاقة، والحوسبة الكمومية و والبات

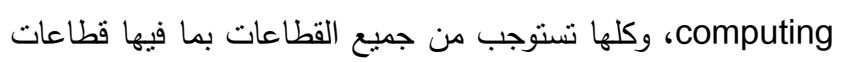
التعليم الاستعداد لها وعمل اللازم حيالها.(41)،(43).

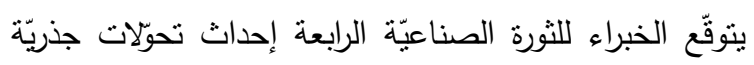

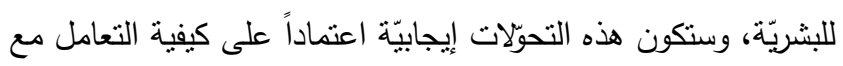

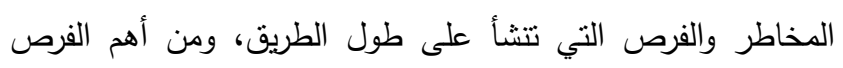

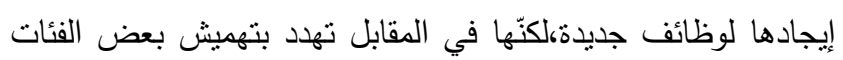

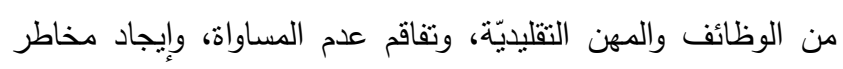

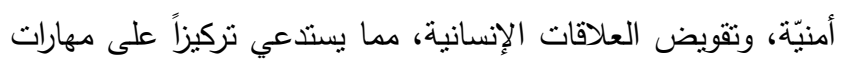

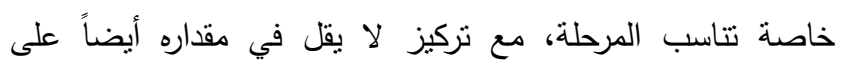

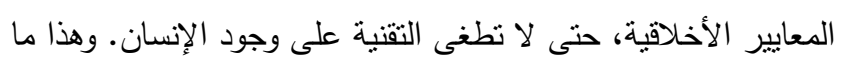
يؤكد عليه شواب(40) من وجوب إدخال القيم والأخلاق في صميم لإني لإنسان وهني
2. توضيح الاهتمام العالمي بمتابعة أداء الجامعات وقياس

أدائها على نواتج التعلّم التي تسعى لإكسابها لخرّيجيها.

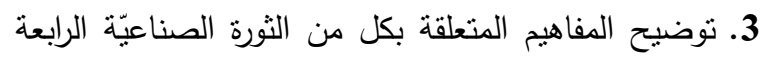
والاعتماد الأكاديميّ.

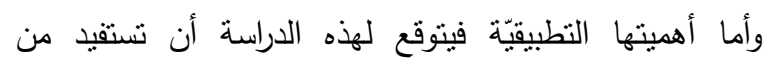

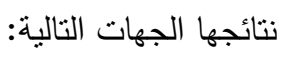
1. المركز الوطني للتقويم والاعتماد الأكاديميّ في مراجعة

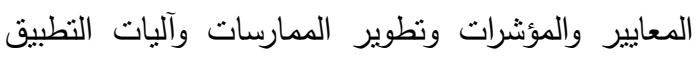
بالاشترالك مع الجامعات السعوديّة.

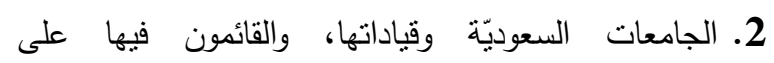
مشروعات الجودة والاعتماد الأكاديميّ؛ لانتهاج السبل

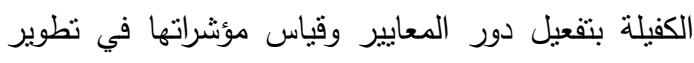
العمليّة التعليمية التعلّمية في الجامعات.

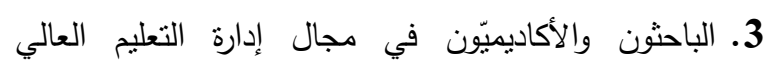
وجودنه، لإجراء المزيد من الدراسات في هذا الثأن.

التعريفات الإجرائية دور الاعتماد الأكاديميّ: الاعتماد الأكاديميّ مجموعة من عمليّات

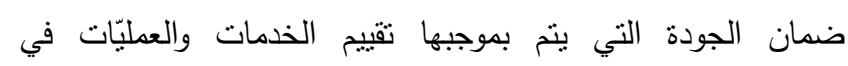
المؤسسات التعليميّة أو البرامج التي تقدّمها، من قبل هيئة خارجيّة

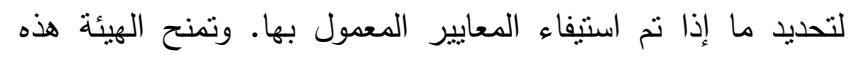

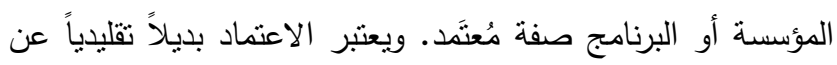

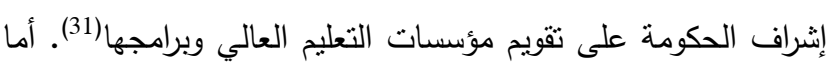

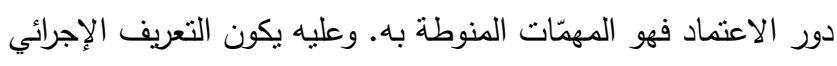

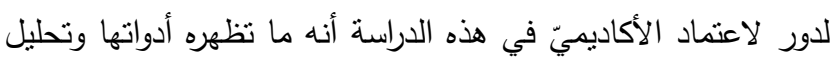

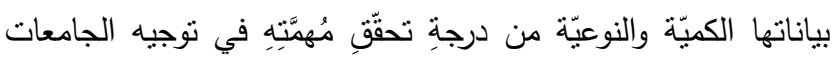

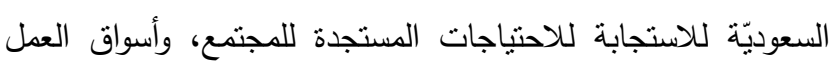

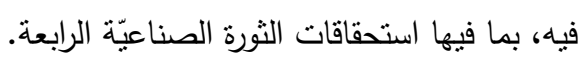
استحقاقات الثورة الصناعيّة الرابعة: الاستحقاق في اللغة العربية

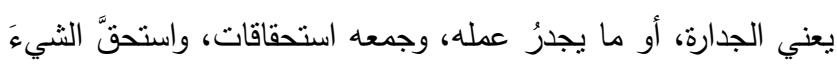

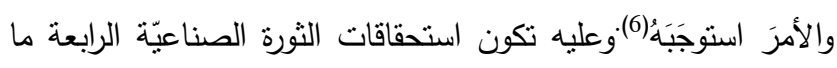

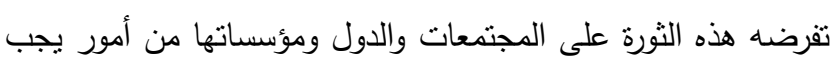
الوفاء بها لمواكبة التغييرات المصاحبة للثورة أو التعايش معها.

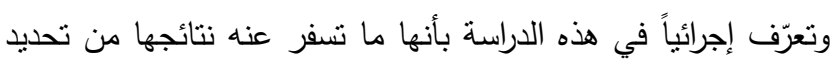

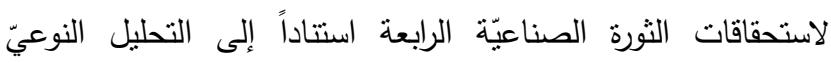

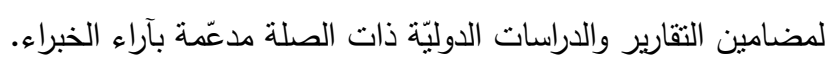

حدود الدراسة

الحدود الموضوعية: تتحدد الدراسة بموضوع دور الاعتماد

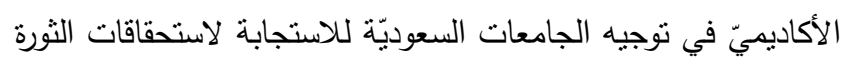
الصناعيّة الرابعة. 
ليقت على قدميه في عالم متغيّر · حيث يرى فسفكيس(45)أن التقنيات

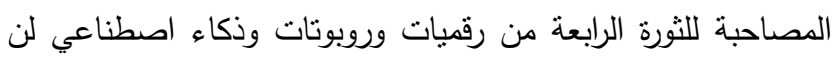
تسبب عجزاً في الوظائف، وإنما أيضا تسبب عجزاً في في المهارتات؛

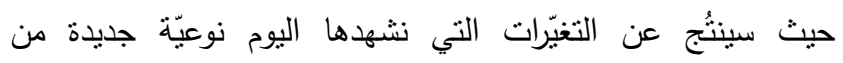

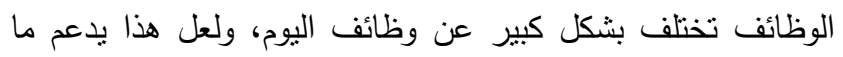
ذهبت إليه دراسة فراي وأوسبورن Frey \& Osborne الوظائف والمهن الأقل عرضة لمخاطر الأتمتة ستكون هي الوظائف والفئ

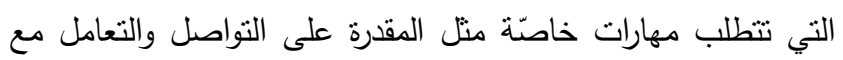

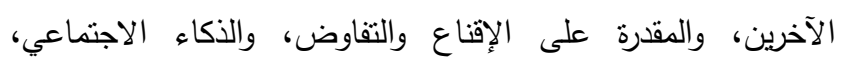

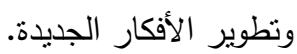

تواجه الدول في ظل هذه الثورة تحديات أهمها أنها مطالبة

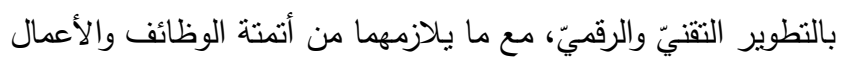

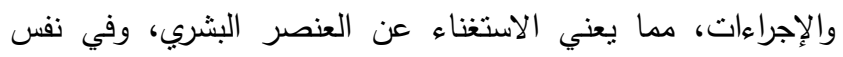
الوقت هي مطالبة بالعمل على نقليل نسب البطالة بين مواطنيها بإيجاد فرص عمل لهذا الزخم الهائل الذي تقذف به الجامعات من

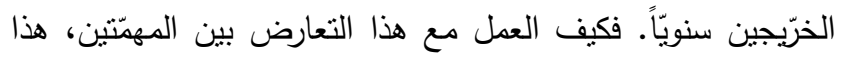
الأمر الذي يدفع بعض الدول إلى التدخل بقرارات وسياسات

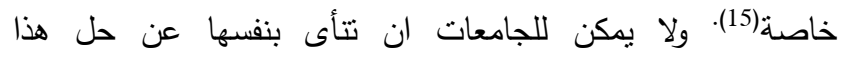

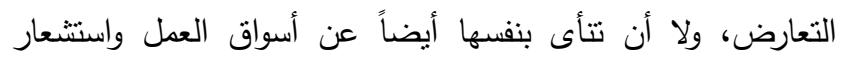

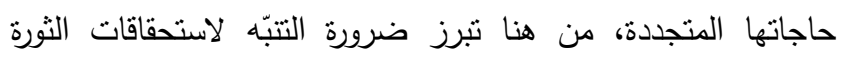

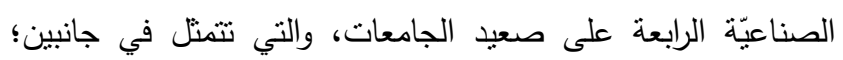

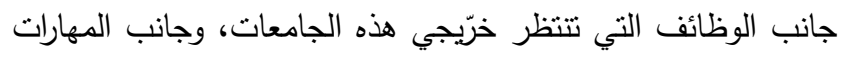

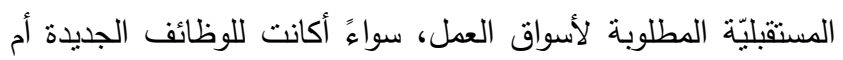

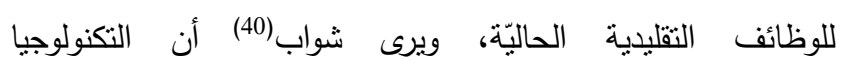

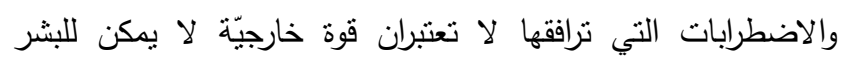

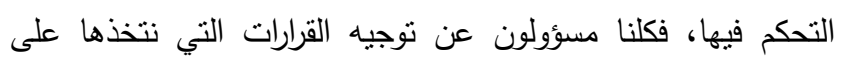

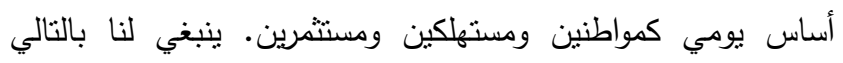

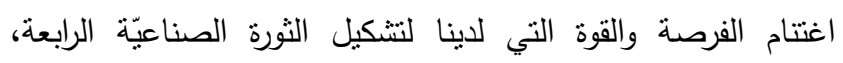
وتوجيهـا نحو مستقبل يعكس أهدافنا وقيمنا المشتركة.

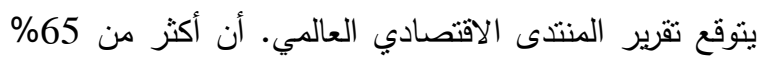
من الطلبة اليوم سوف يعملون في وظائف مستقلبيّة جديدة ومستحدثة،

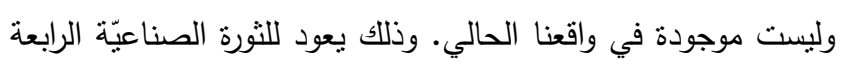

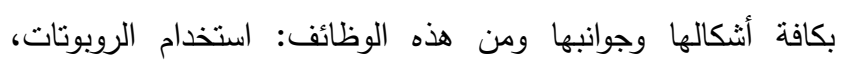
والذكاء الاصطناعي، والطباعة ثلاثية الأبعاد، ومعالجة البيانات كبيرة

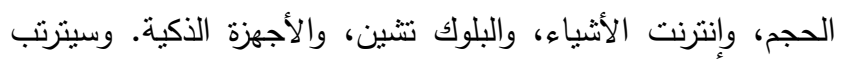
على هذه التحوّلات حاجة ملحّة لنوعيّة خاصيّة من المهارات أهمها:

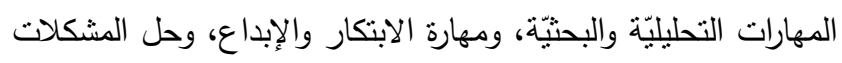

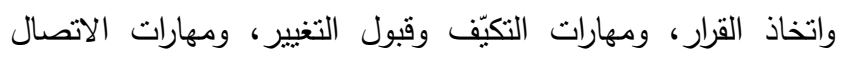

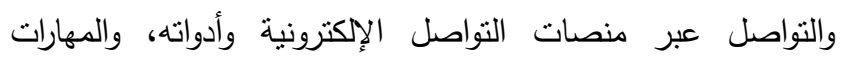

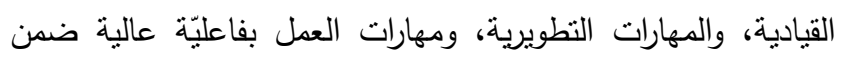

السلوك الفردي والجماعي، وهذا الأمر لا شك منوط بالمؤسسات

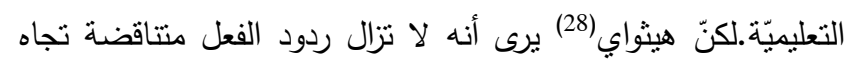

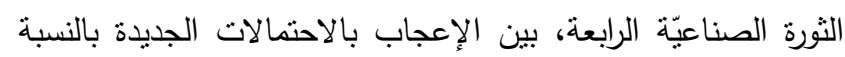

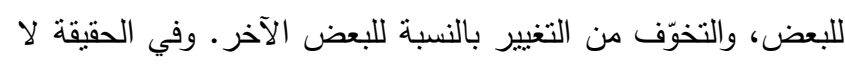

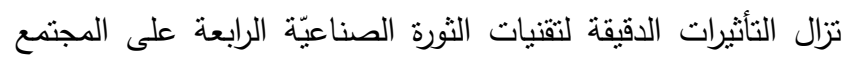

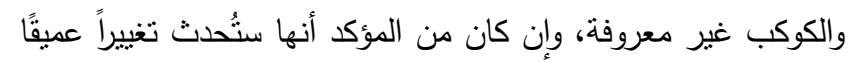

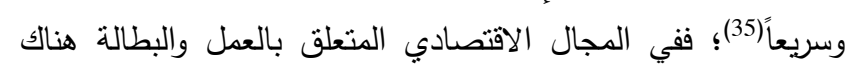

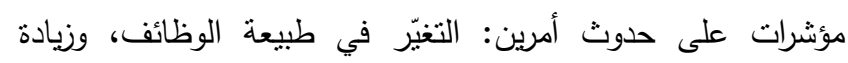
الطلب على مهارات جديدة للموظفين أهمّها المهارات الفكريّة العالية، والمهارات الاجتماعية التي تشمل الإقناع والذكاء العاطفي والمقدرة على تعليم الآخرين (47).

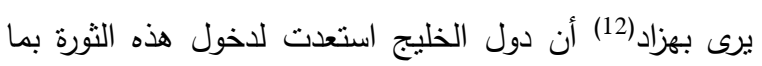

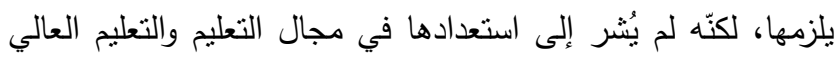

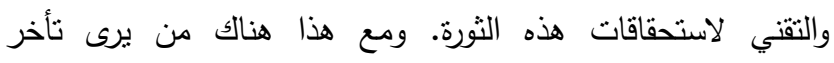
مؤسسات التعليم العربيّة بعمومها في الاستجابة لمنطلبات الثثرة لهاتئ

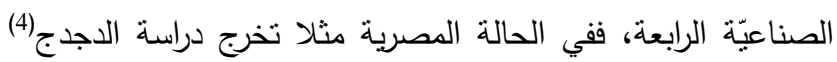

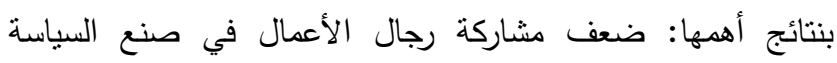

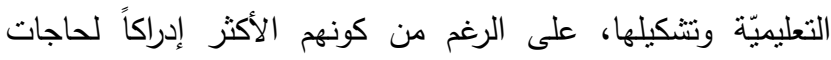

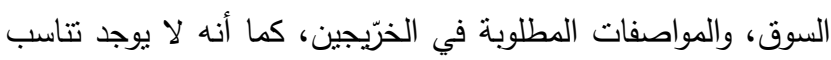

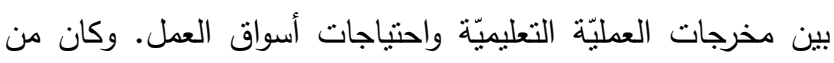

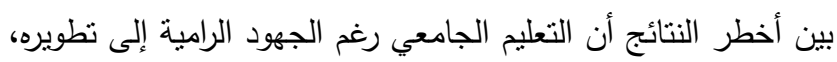

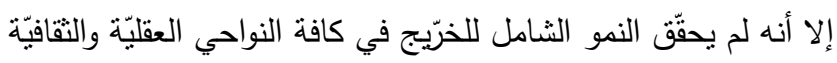

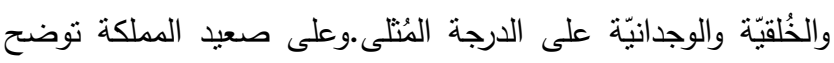

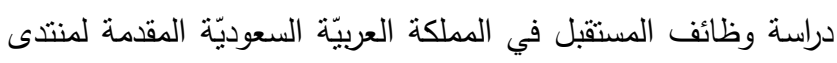

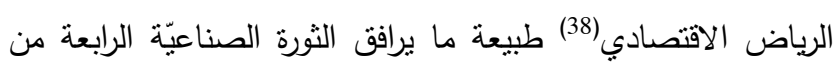

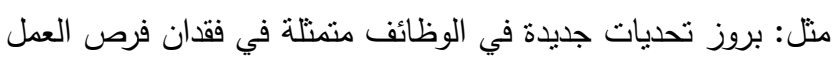

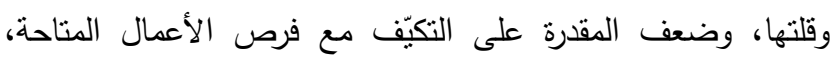

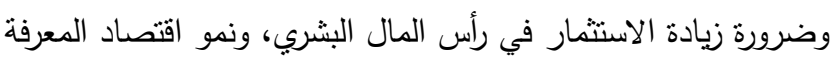

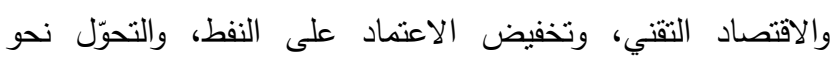
الصناعات البديلة، وتغيير أنماط العمل اليومي.

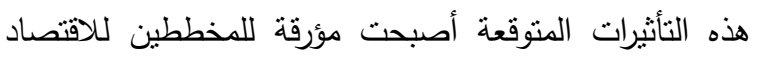
والتتمية وللنظم التعليميّة على اختلافها، وإن لم يتم التعامل دعها جيداً

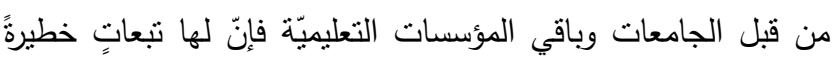

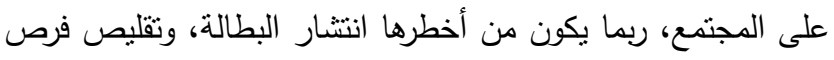

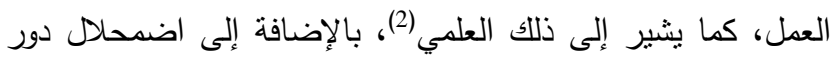

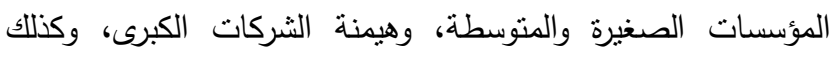

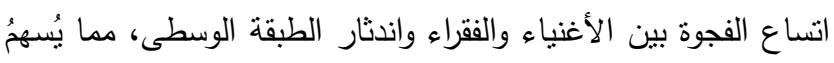

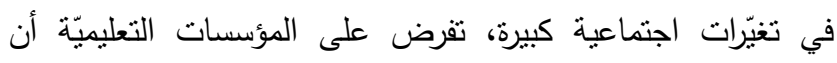

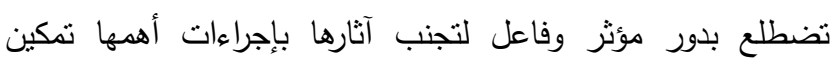

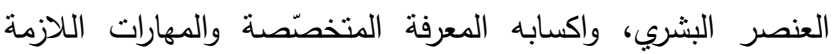


لقد أصبح الاعتماد الأكاديميّ نشاطاً ذا طابع عالمي، حيث لهيث تؤسس له كل دولة هيئة وطنيّة لاعتماد مؤسساتها التعليميّة وبرامجها المختلفة، ويتعدى نشاط بعض الهيئات حدوده الوطنيّة لتمنح الاعتماد لمؤسسات وبرامج دوليّة، وهو ما بطلق عليه اسم الاعتماد الدولي. وتهتم الجامعات في عمومها بالاعتماد الأكاديميّ إدراكا منها لأهميته

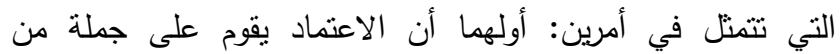
المعايير والمؤشرات التي توّجه نشاط المؤسسات التعليميّة وبرامجها

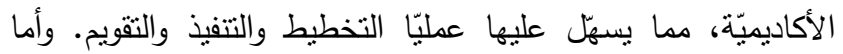
الأمر الثاني فهو أن حصول المؤسسة وبرامجها على الاعتمادات،

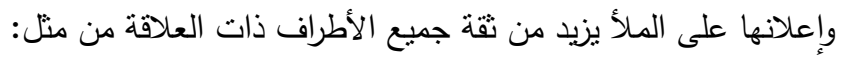
الطلبة، وأولياء الأمور، وأرباب العمل، والجهات الموظّفة للخرّيجين،

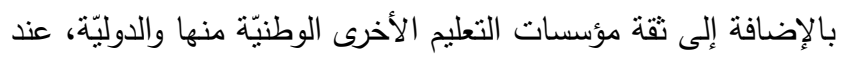

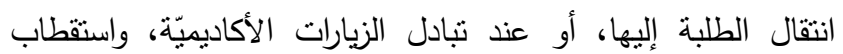
الأساتذة، أو التعاون الدوليّ والثقافيّ فيما بين هذه المؤسسات.

الدراسات السابقة

يتتاول هذا الفصل الدراسات السابقة ذات العلاقة بكل من

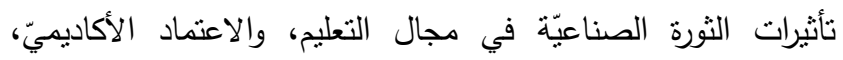

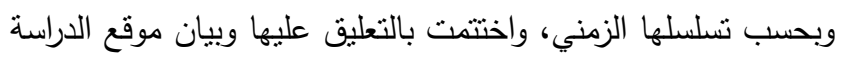

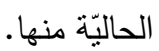
دراسة ثومسون (2019)(44) هدفت تعرُّنَ الكيفيّة التي ينظر بها الثباب السعوديّون لمهارات الوظائف المستقبليّة، كاستحقاقات

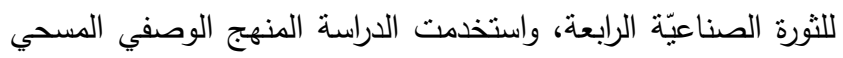

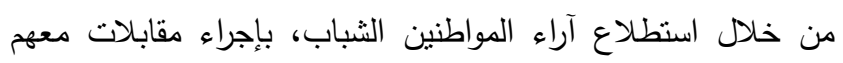
بالإضافة إلى عقد مقابلات ضمن مجموعات بؤريّة، وأكدت النتائج على تزايد إدراك الثباب السعودي للحاجة إلى الاستعداد لآثار الثورة الصناعيّة الرابعة على سوق العمل في المملكة العربية السعوديّة.ووفقاً

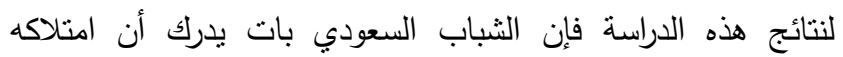

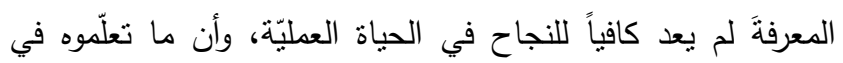

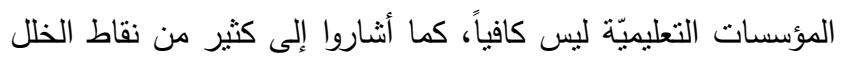

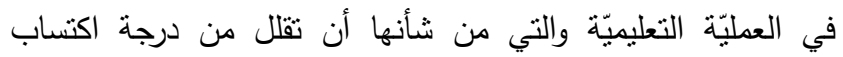
الخرّيجين للمهارات المطلوبة لوظائف المستقبل.

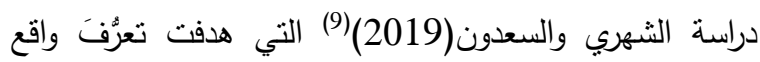

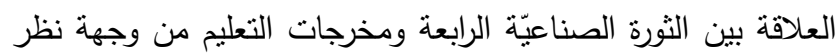

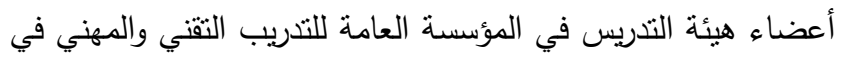

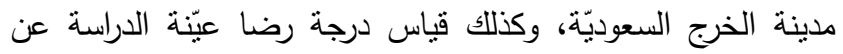

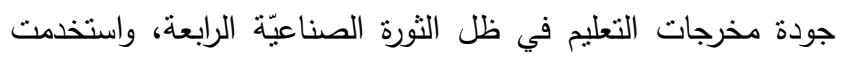

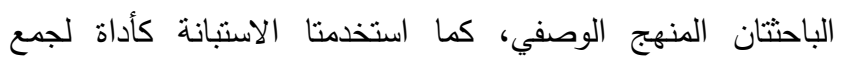
البيانات، وكان من نتائج الدراسة أن نسبة موافقة أفراد العيّنة على بنود النيان

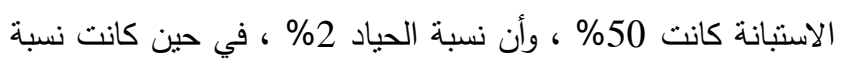

فرق العمل، ومهارات التطوع، ومهارات التفكير الناقد. مهارات التفاوض والتتسيق مع الآخرين، ومهارات الإنصات النشط، والمهارات

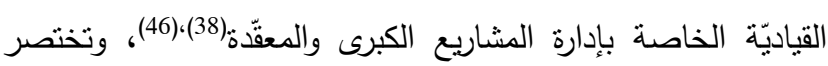

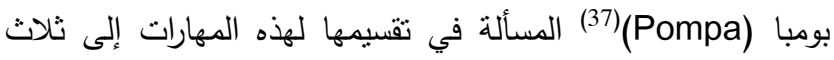
مجموعات رئيسة، هي الأكثر أهمية للنجاح في الحياة اليوم وهي:

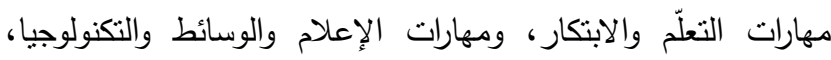
والمهارات الحياتيّة والمهنيّة. لقد تم تقييم الوضع الراهن لسوق العمل والقوى العاملة في

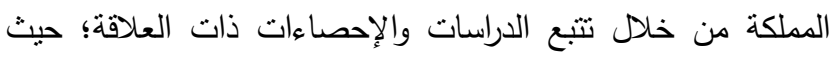
أكدت دراسة ثومسون(44) على تزايد إدراك الثباب السعودي للحاجة

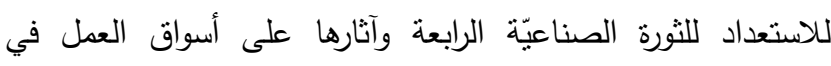

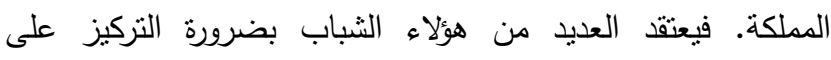

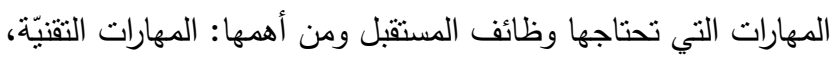

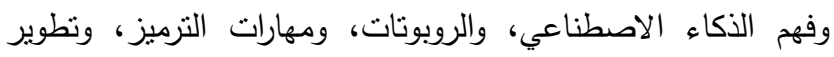

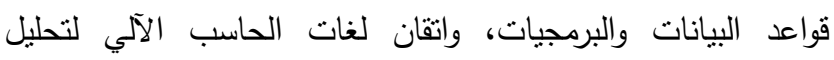
البيانات، وكذلك المهارات المرتبطة بالمقدرة على التحليل، وخفة

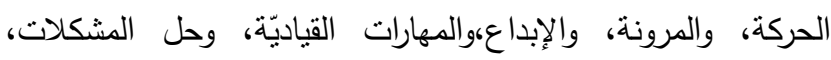

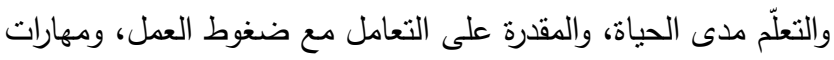

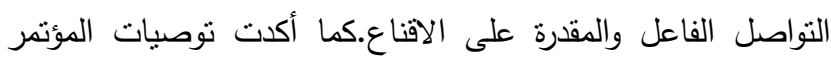

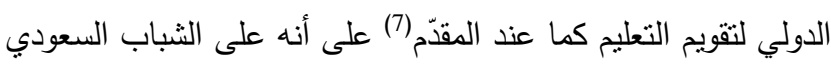

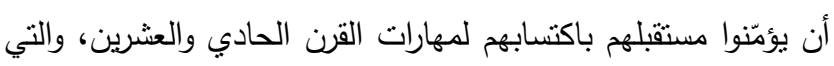
هي مزيج من القُرات الموجودة لديهم والقدرات الجديدة لينجحوا في بئي

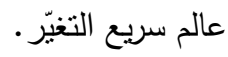

الاعتماد الأكاديميّ

من معاني كلمة اعتماد لغةً الثقةُ، واعتمدَالثيءَ، إذا وافق عليه

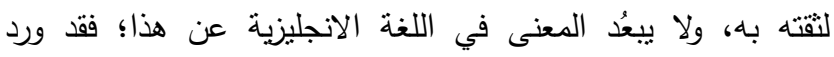

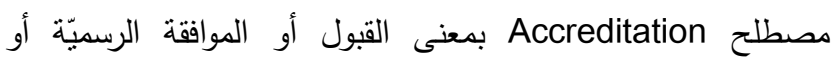

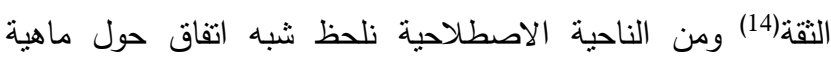

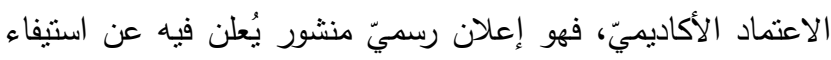

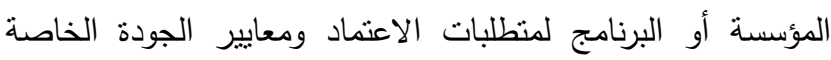

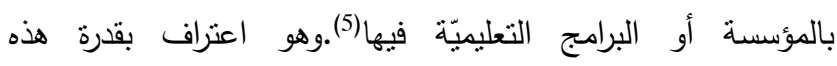

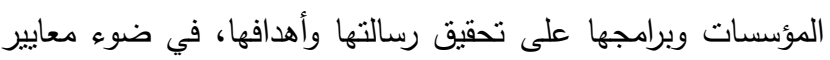

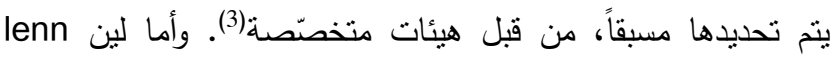

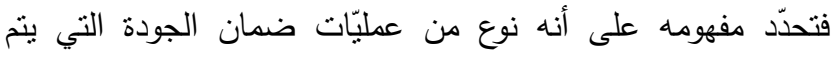

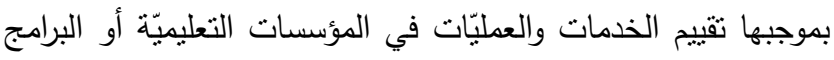
التي تقدمها، من قبل هيئة خارجيّة لتحديد ما إذا تم استيفاء المعايير

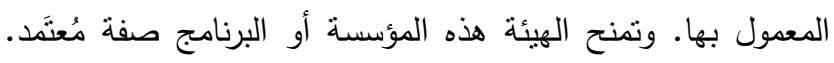

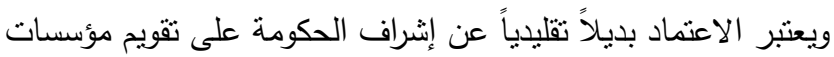
التعليم العالي وبرامجها(31). 
قصديّةٌٌّ من أربع كلّيّات أعمال كنديّة، وجمعت البيانات من مصادر

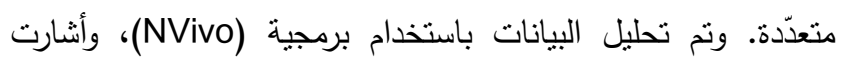

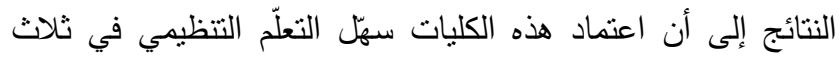

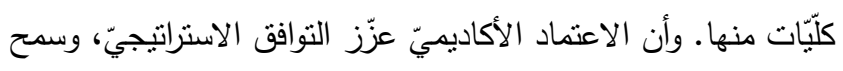

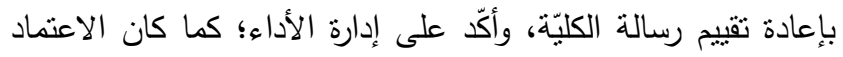

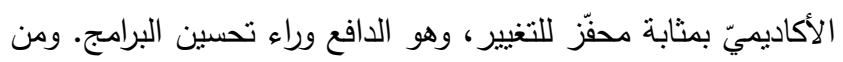
حيث العوامل السياقية، وجدت الدراسة أن للقيادة الدور الأكثر انتشارًا

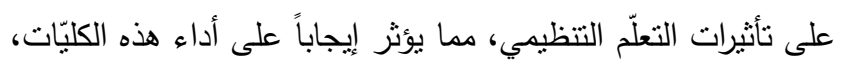

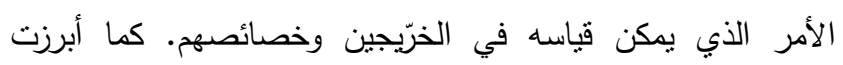
النتائج أهيّة القيادة التعليميّة في نسيليل العمليّات للوصول إلى النتائج

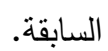

ودراسة دهمان والدجني(2013)(18) التي هدفت نعرُفَت دور

التقييم الخارجي في تطوير أداء كليّات التربية في الجامعات

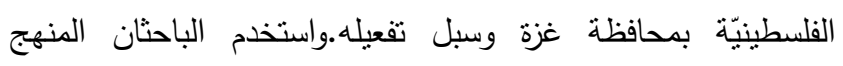

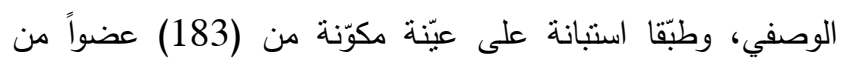

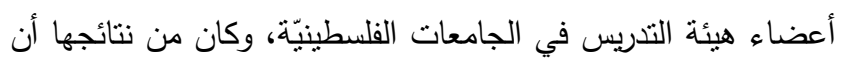
درجة تقديرهم لهذا الدور كبيرة، مما يعني أن لعمليات التقييم الخارجيّة دوراً في تطوير أداء كليّات التربية في الجامعات الفلسطينيّة.

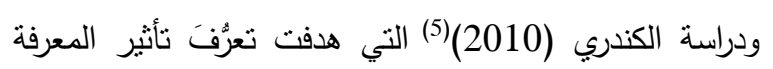
باحتياجات سوق العمل على تحسين أبعاد جودة الخدمات التعليميّة.

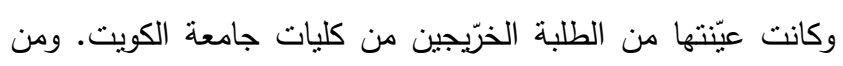

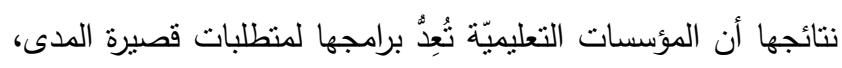

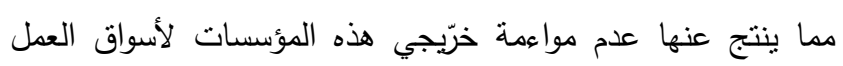

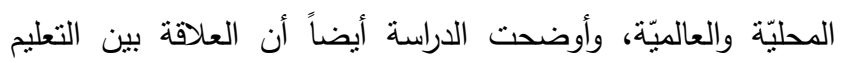

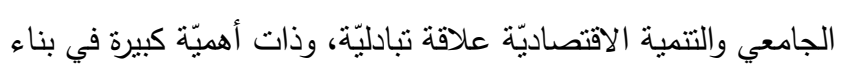

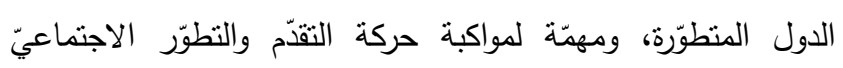

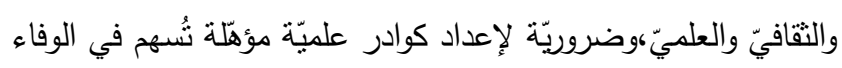

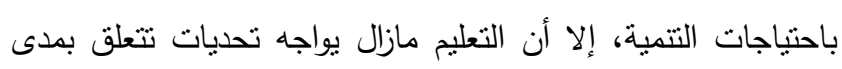

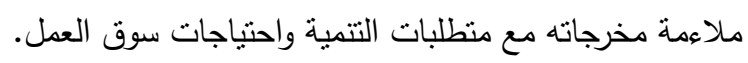

\section{التعليق على الدراسات السابقة}

من خلال النظر في الدارسات السابقة يُلحَظُ أنها كلّها استخدمت المنهج الكميّ (الوصفي) سوى دراسة إليوت وقو ( Elliot \&

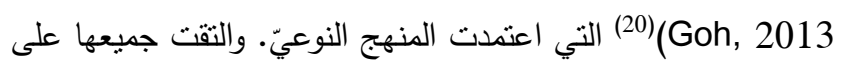
دراسة مدى ملاءمة مخرجات التعليم لحاجات أسواق العمل بشكل التهل

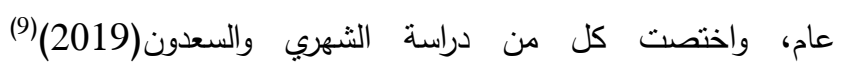

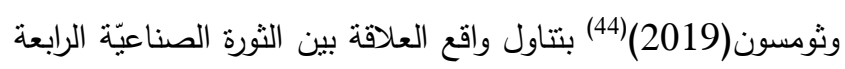
ومخرجات التعليم من حيث المهارات التي تنطلابها الوظائف التي تأتي لتوني

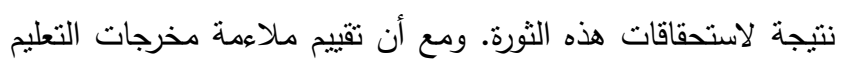
لحاجات أسواق العمل هو المحور الرئيس الذي تدور حوله عمليّات

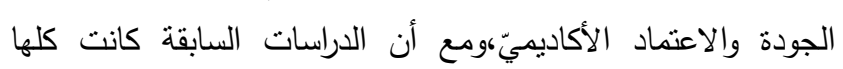

رفض بنودها 30\%. مما يستوجب إعادة النظر في العمليات والإجراءات لزيادة درجة مواءمة الخرّيجين ومهاراتهم لأسواق العمل.

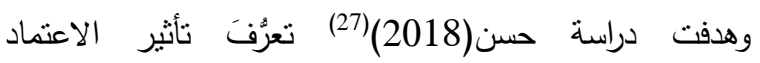
الأكاديميّ في تلبية احتباجات سوق العمل في الكليّة التقنيّة الإداريّة

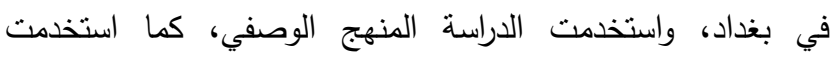

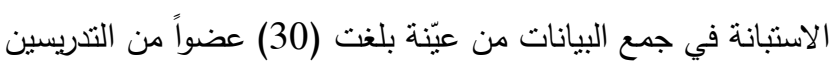

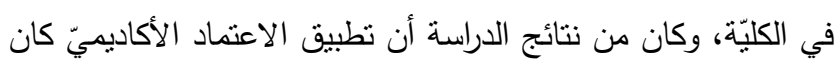

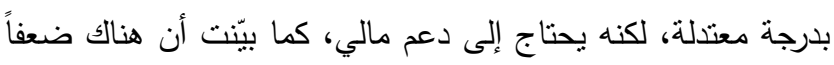
في آليات التتسيق مع أسواق العمل لمعرفة احتياجاتها الحقيقيّة.

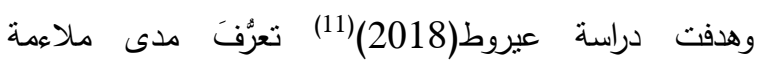
التخصصات التي تطرحها الجامعات الأردنية الرسميّة لمواكبة حاجات ملات

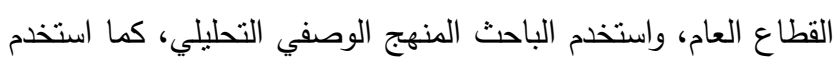

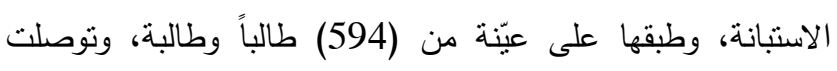

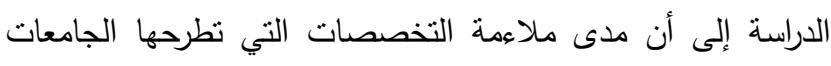

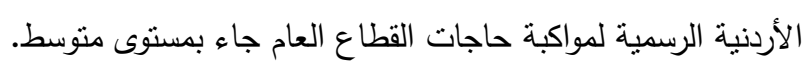

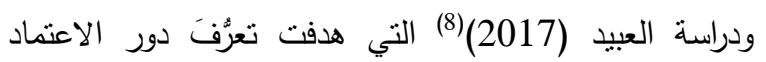
الأكاديميّ في ضبط جودة معايير الجودة الثاملة في مؤسسات التعليم العالي في الوطن العربي بشكل عام، ولم تخصص دولة دولة بعينها،

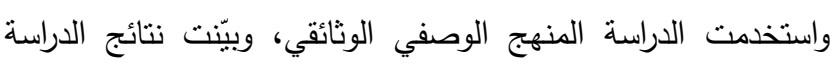

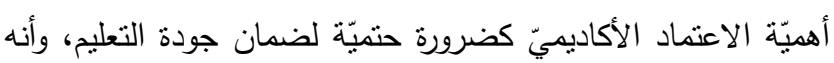

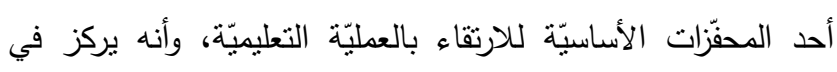

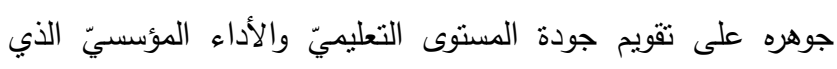

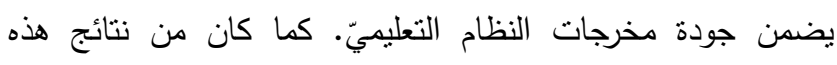

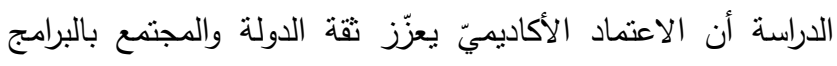
الأكاديميّة. ودراسة حمزة (2015)(24) التي هدفت تعرُّنَ مدى مواءمة مخرجات الجامعات السعوديّة لاحتياجات سوق العمل، واستخدم

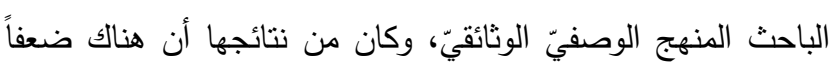

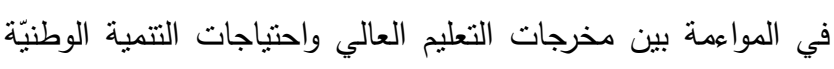

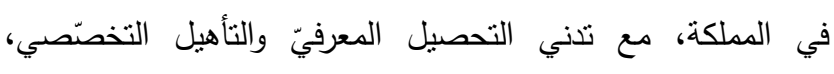

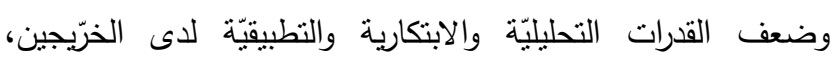
والقصور في تعزيز القيم والاتجاهات الإنتاجية. إضافة إلى نخريّيج

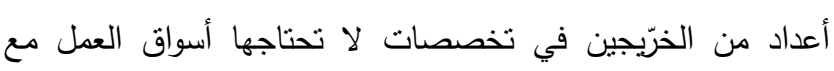

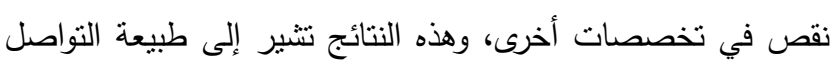

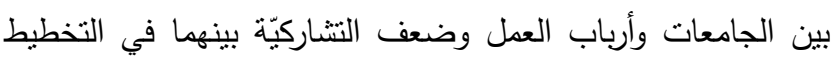
لنواتج التعلّم التي يتسلح بها الخرّيجون. وهدفت دراسة إليوت وقو (Elliott \& Goh, 2013) استكثافت أثز الاعتماد على التعلّم التتظيميّ كما براه المسؤولون وأعضاء هيئة التدريس في كليات الأعمال في الجامعات الكنديّة.

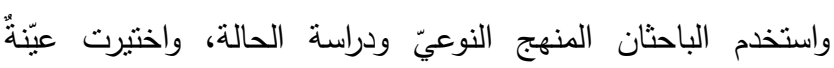


تمت إجراءات الدراسة وفق ما يلي من عمليات وخطوات:

\section{منهج الدراسة}

Mixed Methods اعتمدت الدراسة الحالية المنهج المزجي Research وأهدافها، ولما يمتاز به هذا المنهج من مزايا أهمّها:تجاوز الاكتفاء

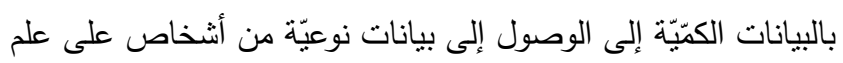

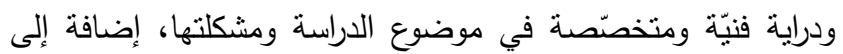
مناسبته للاراسات الني يقوم بها باحثون على صلة وثيقة بمشكلة الدراسة، حيث للباحث في الدراسة الحاليّة خبرة تزيد عن عثر سنين

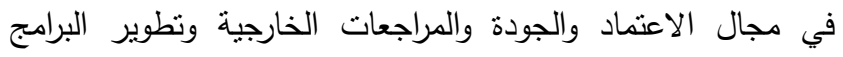

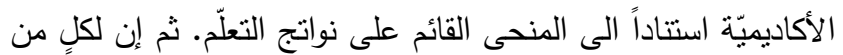

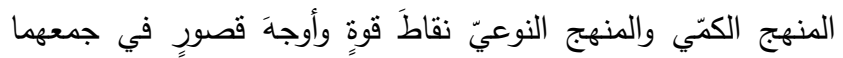
للبيانات، في حين يكون المنهج المزجيّ جامعاً لنقاط القوة في كلا

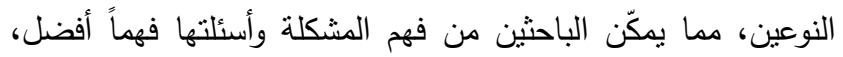

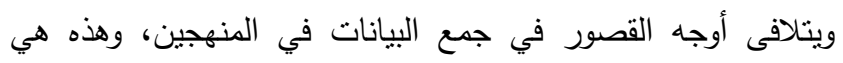

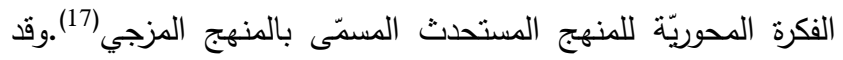
اختار الباحث من تصاميم البحث المزجيّ"التصميم المزجيّ التتابعي

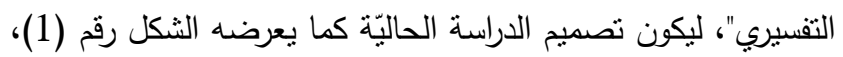

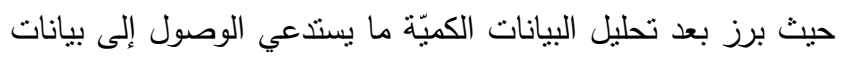
نوعيّة تفسّرها وتوضتحُها بصورة أدق، وهذا سبب قوي لاختيار هذا لكان

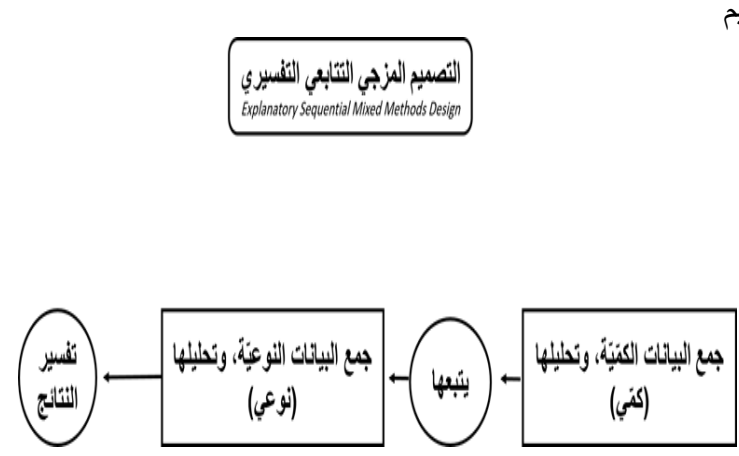

شكل1: تصميم الاراسة الحاليّة (Creswell, 2014, 270)

\section{المجتمع والعيّة}

تكوّن مجتمع الدراسة من الجامعات السعوديّة الحكوميّة، وتم

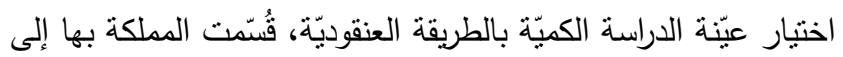
ست مناطق من حيث توزّعُ هذه الجامعات، لتكون وحدة العيّنة مجموعة الجامعات في المنطقة الواحدة، وبطريقة عشوائية اختيرت العاصمة (الرياض) من بين هذه الست، وعليه تكون كل جامعاتها

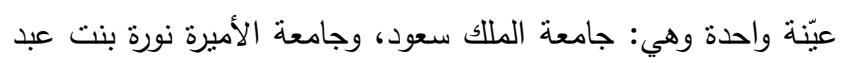
الرحمن، وجامعة الإمام محمد بن سعود الإسلاميّة. وطبقت أداة الدراسة على العاملين فيها في الجودة والاعتماد الأكاديمي، حيث نم
معنيّة بهذا، إلا أن بعضها كان أكثر تصريحاً بذلك مثل: دراسة

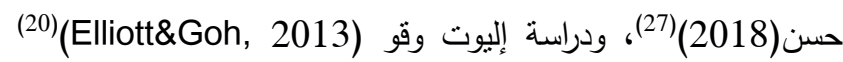
ودراسة العبيد (2017)(8)، وذلك من خلال تناولها لتأثير الاعتماد الأكاديميّ على هذه المخرجات ومواءمتها مع الحاجات المتجددة

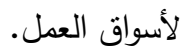

وتختلف الدراسة الحاليّة عن سابقاتها في تركيزها على عيّنة

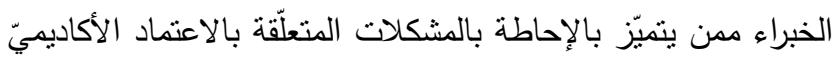

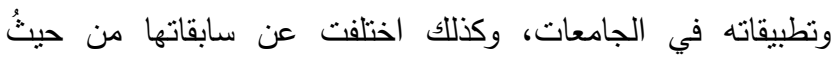

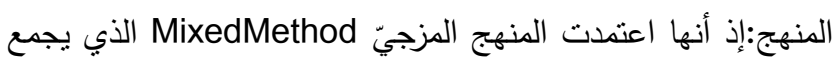
بين المنهج الكميّ والمنهج النوعيّ للوصول إلى ما هو أعمق من

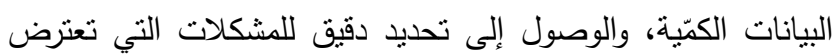

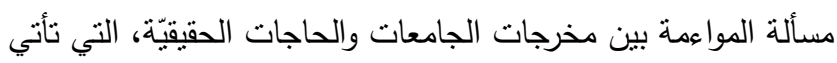
استحقاقاً للتورة الصناعيّة الرابعة. كما تتميّز هذه الدراسة بإبرازها لقيمة

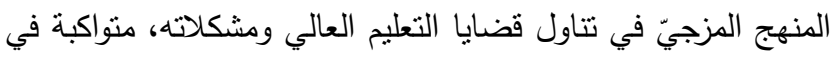

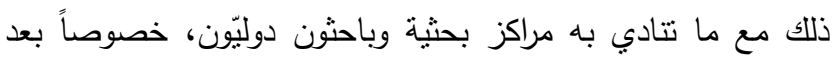

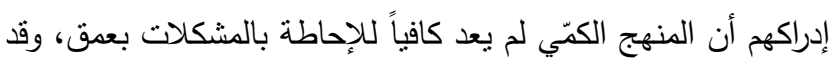

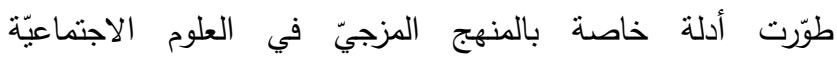

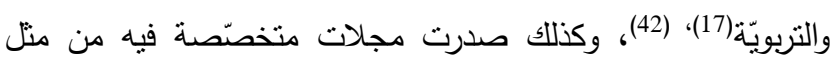

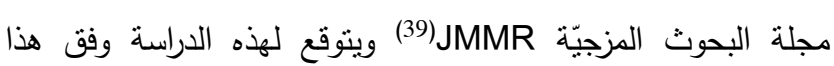

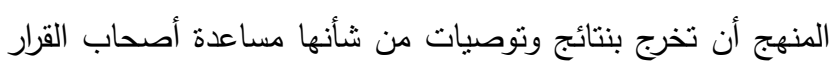

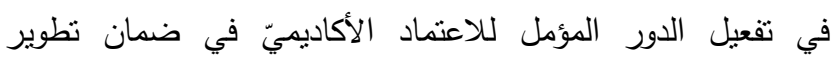
مخرجات الجامعات بما يخدم مجتمعاتها. وتختلف الدراسة الحاليّة عن سابقاتها في تركيزها على عيّنة

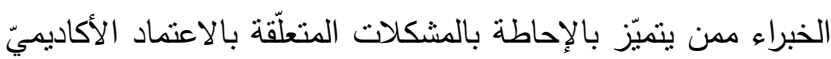

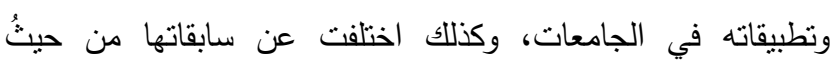

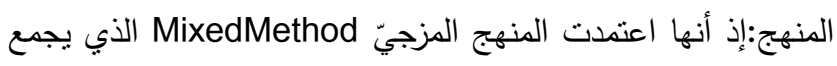

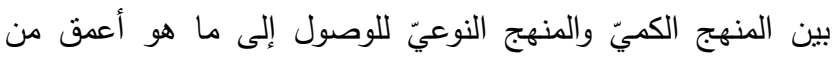

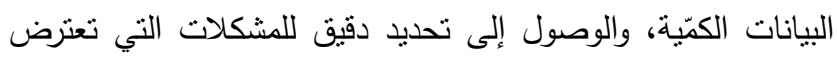

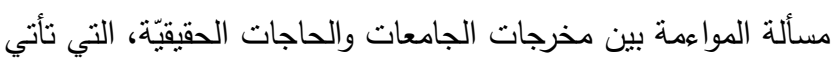
استحقاقاً للثورة الصناعيّة الرابعة. كما تتميّز هذه الدراسة بإبرازها لقيمة

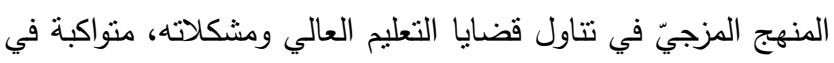

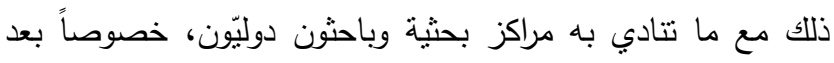

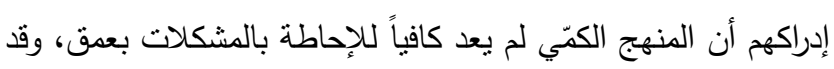

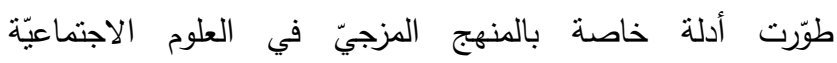

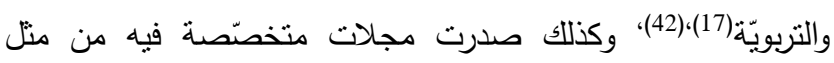

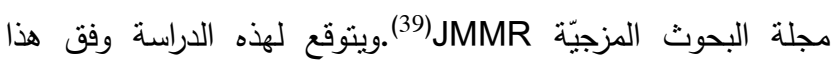

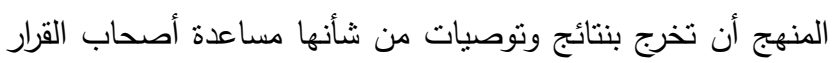

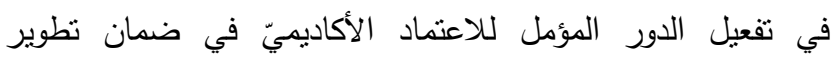
مخرجات الجامعات بما يخدم مجتمعاتها. الطريقة والإجراءات 
الصياغة، والملاءمةُُ للُبعد الذي جاءت فيه. وقد أُعيدت صياغة بعض

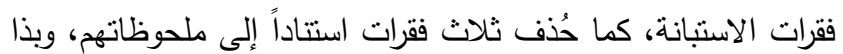
أصبحت الاستبانة مكوّنة من(20) فقرة موزّعة على أربعة أبعاد هي: كفاية المعايير والأدلة الإرشاديّة، وشمولية المعايير والأدلة الإرشاديّة

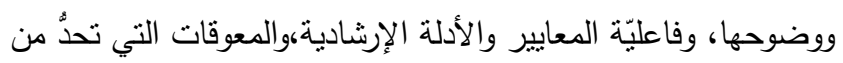
دور الاعتماد الأكاديميّ، وفي كل بعد منها (5) فقرات. وبخصوص الصدق النوعيّ يوصي كرسويل بن Creswell النوعيّ validitystrategies، وقد استخدم الباحث منها استراتيجيتين هما: متابعات المستجييين memberschecking للتحقق من نتائج

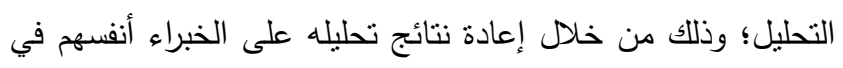

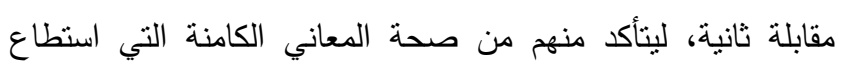

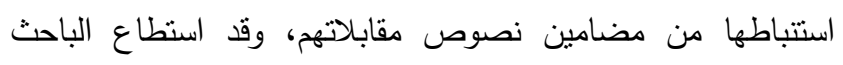

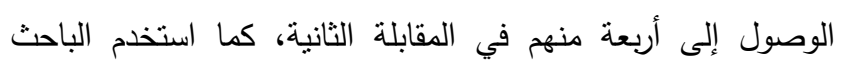

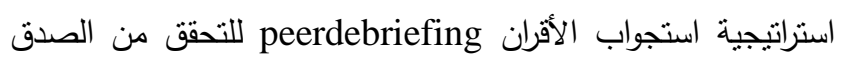

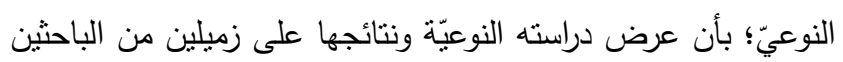

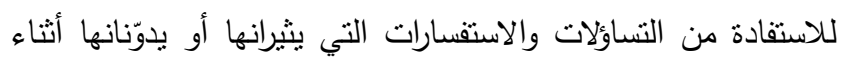

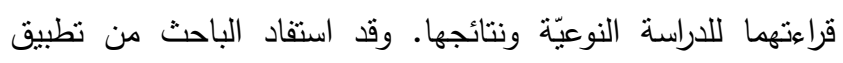

هاتين الاستراتيجيتين في التحقق من بعض الصياغات وضبطها.

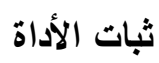

تم التحققُ من ثبات أداة الدراسة الأولى(الاستبانة) بعد نطبيقها

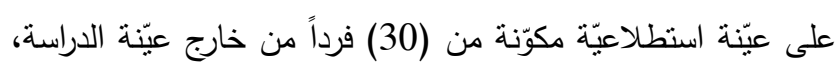
وتم احتساب الاتساق الداخلي لها، وباستخدام معادلة (كرونباخ ألفا)

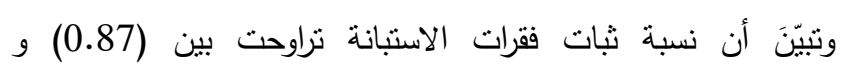
(0.89)، وكان الثبات الكلّي لها (0.88). ثم نم حسابه بطريقة التجزئة النصفيّة، حيث بلغ (0.88) وهذه القيم مقبولة لاعتماد الأداة لجمع بيانات الدراسة.

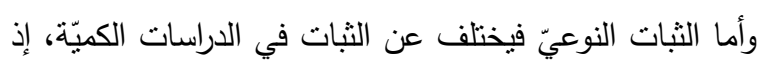

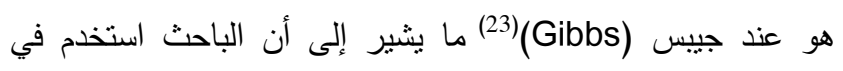

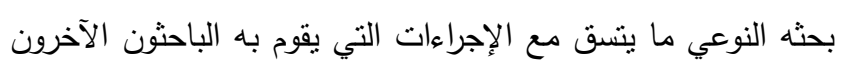

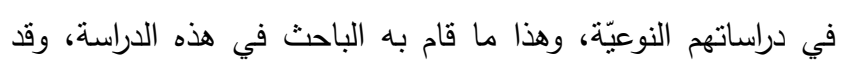
وثق تلاك الإجراءات، ومن بينها الموثوقية أو الصدق النوعيّ كما بيّن أعلاه. وقد حرص الباحث على نوثيق المراجع العلميّة التي بستند إليها لإنيا في تللك الإجراءات.

تم تحديد الاستجابة على فقرات الاستبانة بخمسة مستويات،

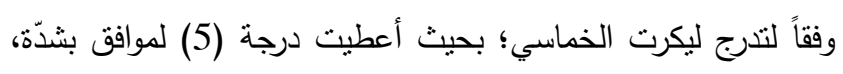

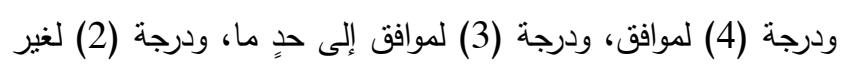

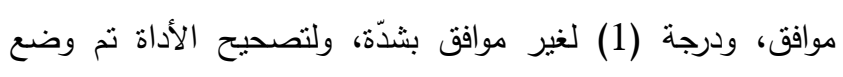

توزيع 170 استبانة،وكان عدد الاسنبانات الصالحة للتحليل منها

125 استبانة.

أما عينّةُ الدراسة النوعيّة فتكوّنت من ستة خبراء ممن بعملون أو سبق لهم العمل كمستشارين للمركز الوطني للتقويم والاعتماد

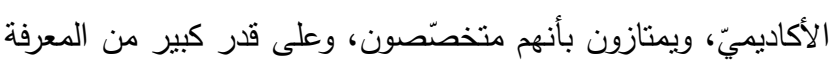

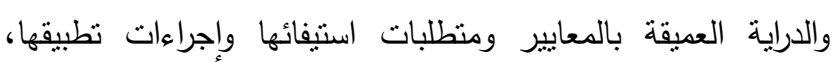

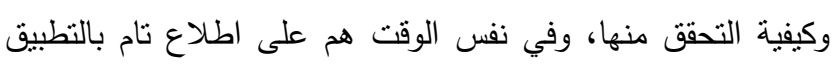

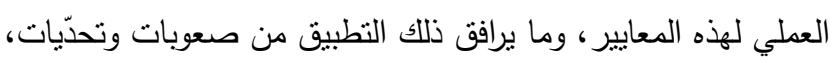

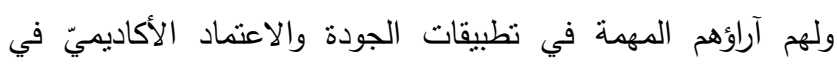
الجامعات استتاداً إلى خبراتهم كمحكمين ومراجعين ينتدبهم المركز

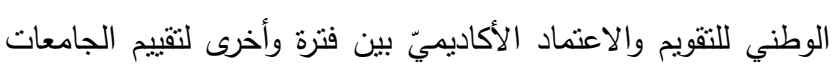

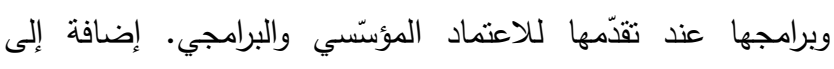
معرفتهم بأحوال الجامعات وتطوراتها،كونهم في الأصل أعضاء هيئات تدريس مارسوا مهام مناصب عليا في جامعاتهم وتحديداً في مجال

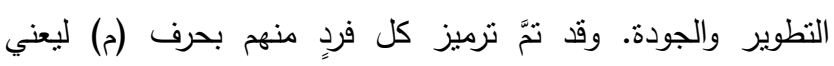

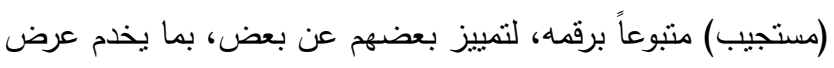
نتائج المقابلات ومناقثتها. أداة الدراسة ولتحقيق هدف الدراسة الرئيس نم استخدام أداتين هما:

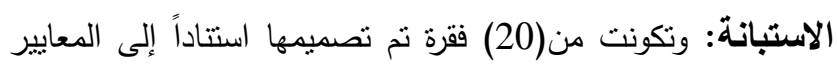

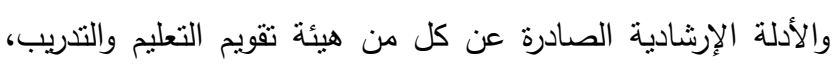

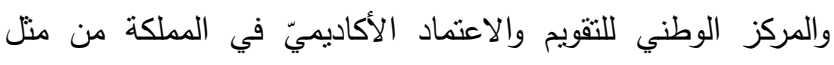

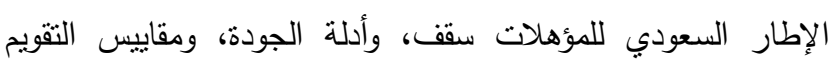

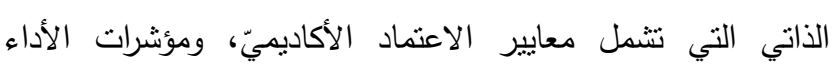

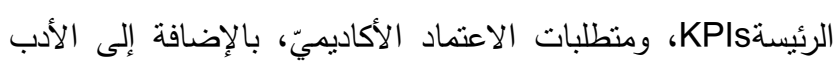

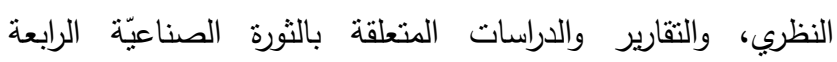
واستحقاقاتها في مجال التعليم العالي ومؤسساته.

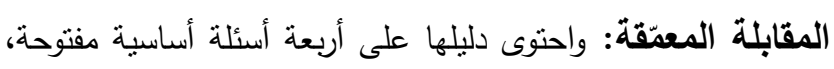

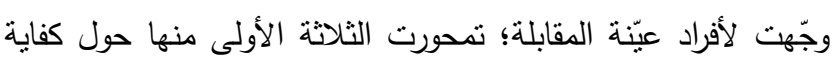

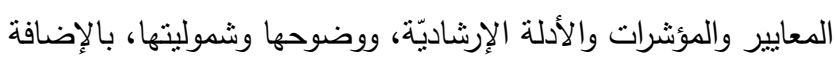
إلى فعاليّتها في تحقيق دورها في توجيه الجامعات لمواءمة خرّيجيها

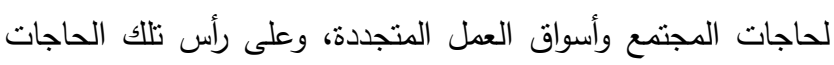

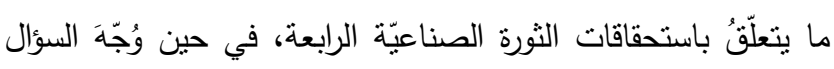

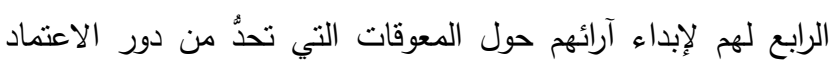

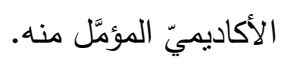

صدق الأداة - - مداة

نم التأكد من الصدق الظاهريّ لأداة الدراسة الكميّة بعرضها في

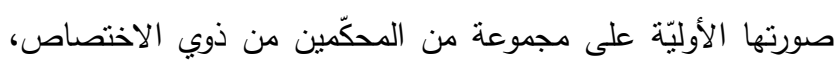

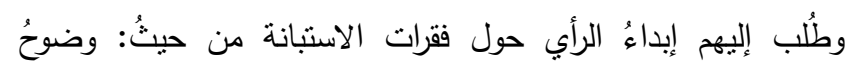


2. .الاستعداد للتغيّر في طبيعة الوظائف، حيث إن هذه الثورة

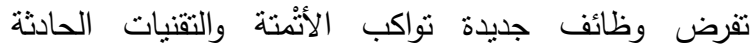

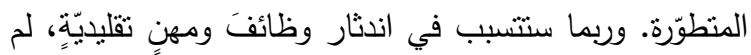

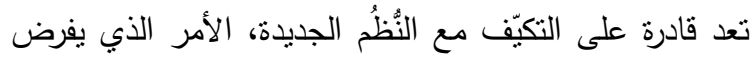
على الجامعات أن تأخذ هذا الأمر في الحسبان عند التخطيط

$$
\text { لمخرجاتها. }
$$

3. التركيز على البحث العلميّ النطبيقيّ والابتكار ورعايتهماهبما يخدم القضايا والمشكلات المستجدّة.

4. بناء منظومة من القيم الأخلاقية ومُعزّزات الهويّة، حفاظاً عليها من الاستلاب والتأثر بتبعات الرقمَنة، والمتغيرات النقافيّة المُعَلَهَة التي ترافق الثُرة الصناعيّة الرابعة.

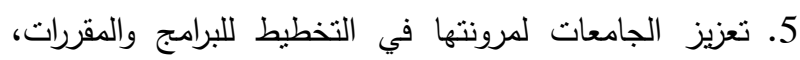

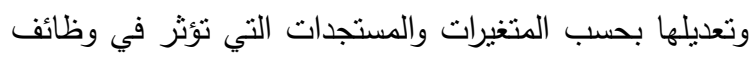
المستقبل والمهارات المطلوبة لها. 6. السعي لتحقيق نتاركيّة فاعلة في التخطبط لمخرجات البرامج

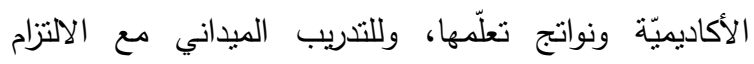
بالثفافيّة في المتابعة بين الجامعات وأرباب العمل.

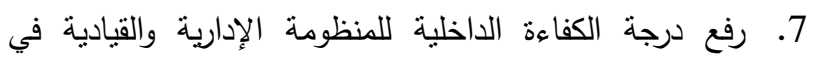

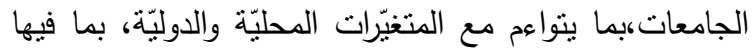
ما تفرضه الثورة الصناعيّة الرابعة. الاهتمام بمهارات مخصوصة تتاسب الوظائف والأعمال الجديدة.

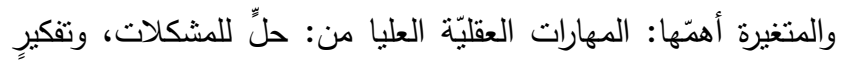

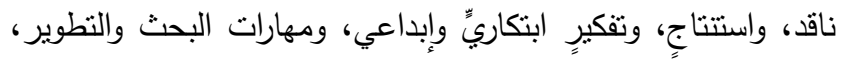

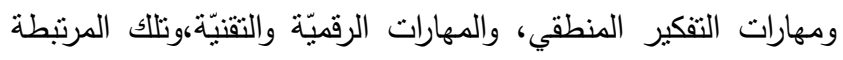
بالذكاء الاصطناعي، والمهارات الخاصِّة المرتبطة بتقنية المعلومات من حيث المقدرة على جمعها ومعالجتها، والمهارات الوجدانيّة

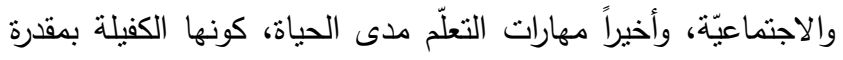

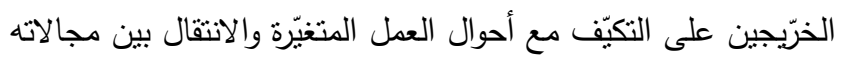
بسلاسة.

نتائج السؤال الثاني: ما درجة إسهام الاعتماد الأكاديميّ في

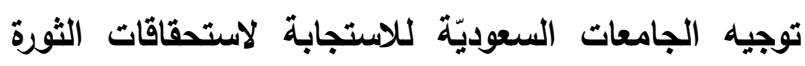

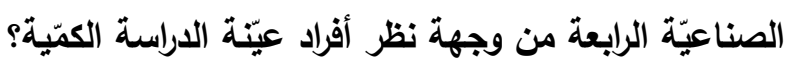
من أجل الإجابة عن هذا السؤال تمّ احتساب المتوسّطات

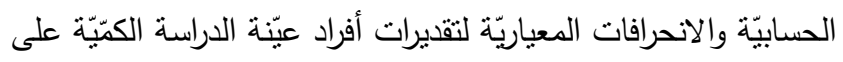

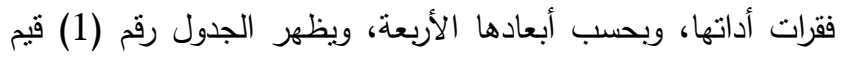
هذه المتوسّطات.
تقديرات (درجات قطع) تستتد إلى المعادلة التالية:(5-1) ٪3= 1.33 وهو الفرق بين كل درجة وأخرى، وعليه تكون درجة الموافقة منخفضة المعادة

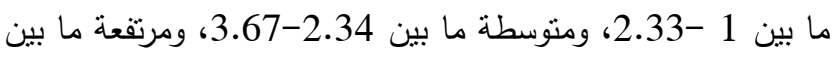
.5-3.68

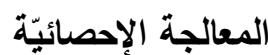

تم معالجة البيانات الأولية للدراسة وتحليلها كما يلي:

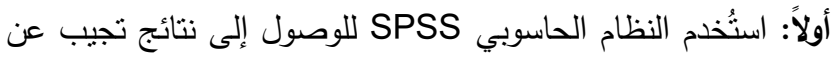
أسئلة الدراسة الكمّيّة وفق المعالجات التالية: • • استخدام معادلة (كرونباخ ألفا) للتحقق من ثبات الأداة.

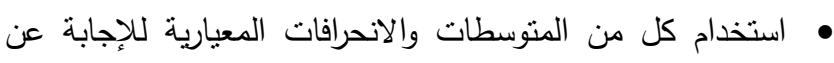

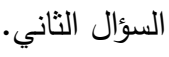

ثانياً: بخصوص البيانات النوعيّة فقد استخدم الباحث النظام الحاسوبي (Nvivo) )، كما هو مبين في مقدمة إجابة السؤال الثالث. نتائج الاراسة ومناقشتها تم في هذا الفصل إيراد نتائج الدراسة، والتي تنكل إجابات عن

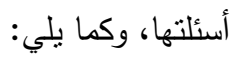

\section{نتائج السؤال الأول: ما استحقاقات الثورة الصناعيّة الرابعة في

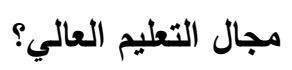

للإجابة عن هذا التساؤل تتبع الباحثُ الأدبَ النظري ذا الصلة،

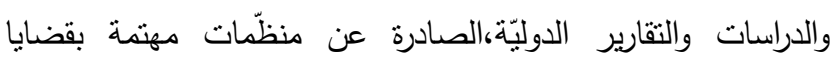

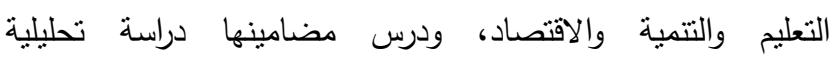
(استتباطية)، بهدف تحديد أهم استحقاقات الثورة الصناعيّة الرابعة، ودئة وتبيّن أن استحقاقاتها كثيرة واسعة نطال المجالات الاقتئهاديّة

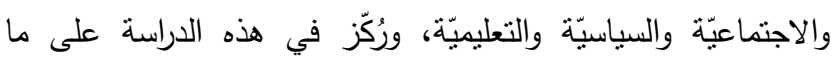

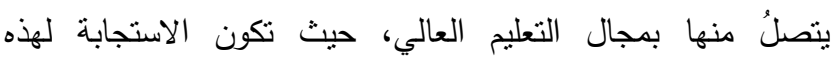
الاستحقاقات ضرورة ملحّة أمام الجامعات.وقد أعدّ الباحث فيها قائمةً عرضها على مجموعة من الخبراءالمتخصصين ممّن سبق لهم العمل فئل

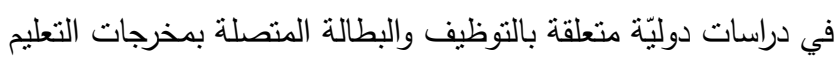

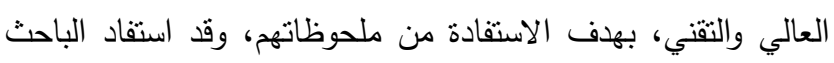

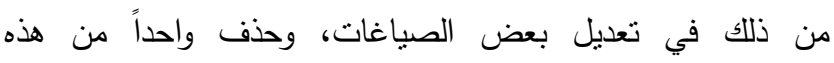

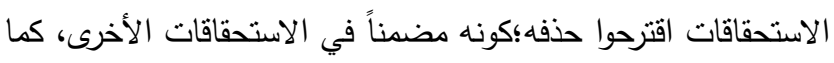

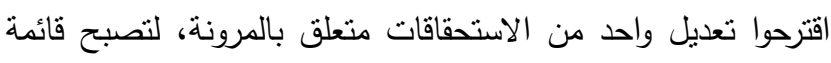

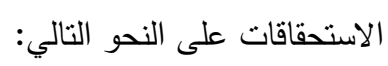
1. الاستشراف المستمر للتغيّرات في أسواق العمل في القطاعات العات

$$
\text { العامة والخاصة وغير الربحية. }
$$

\begin{tabular}{|c|c|c|c|c|c|c|}
\hline الموافقة درجة & الرتبة & الحسابي المتوسط & $\begin{array}{l}\text { الانحعياري } \\
\text { الانحراف }\end{array}$ & مجموع الفقرات متوسط & البعد & الرقم \\
\hline
\end{tabular}

جدول 1: المتوسّطات الحسابيّة والانحرافات المعياريّة لأبعاد الاستبانة الأربعة. 


\begin{tabular}{|c|c|c|c|c|c|c|}
\hline الموافقة & 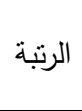 & الحسابي المتوسط & المعياري الانحراف & مجموع الفقرات متوسط & 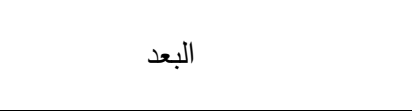 & 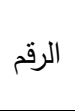 \\
\hline 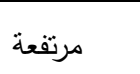 & 3 & 3.88 & 3.39 & 19.40 & كفاية المعايير والأدلة الإرشاديّة & .1 \\
\hline 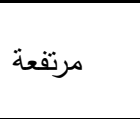 & 2 & 3.90 & 2.89 & 19.51 & شمولية المعايير والأدلة الإرشاديّة & .2 \\
\hline 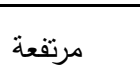 & 3 & 3.88 & 3.21 & 19.38 & فاعليّة المعايير والأدلة الإرشاديّة & .3 \\
\hline 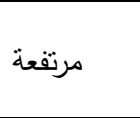 & 1 & 4.46 & 2.93 & 22.32 & المعوّقات التي تحدّ من دور الاعتماد & .4 \\
\hline 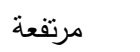 & \multicolumn{2}{|c|}{4.03} & \multicolumn{4}{|c|}{ ستط الكلّي للأبعاد } \\
\hline
\end{tabular}

تتظيمية وادارية، وبعضها الآخر راجع إلى أسباب مالية تكاد تكون

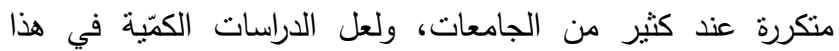

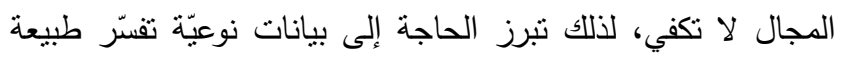
الفجوة وتوضح أسبابها. وسيأتي بيان ذلك في إجابة السؤالين الثالث

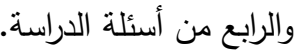
نتائج السؤال الثالث: ما درجة إسهام الاعتماد الأكاديميّ في

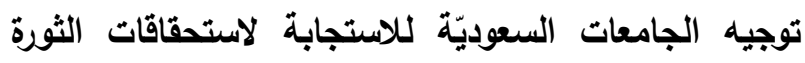
الصناعيّة الرابعة من وجهة نظر الخبراء؟

تمت الإجابة عن هذا السؤال من خلال التحليل النوعيّ للبيانات التي جاءت في إجابات أفراد عيّنة المقابلة على الأسئلة الأربعة

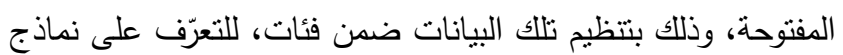

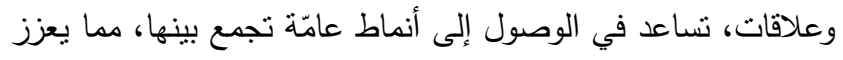

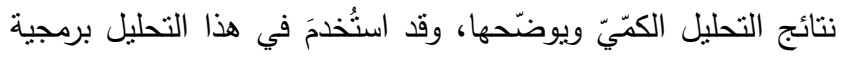

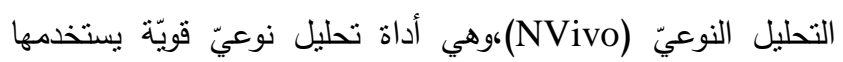

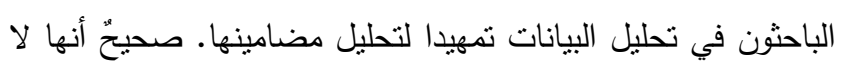
تتوب عن الباحث في العمل الفكريّ لتحديد ما تعنيه البيانات، لكنها

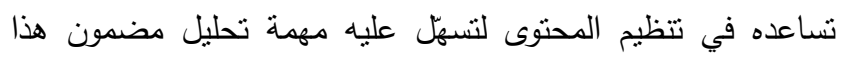

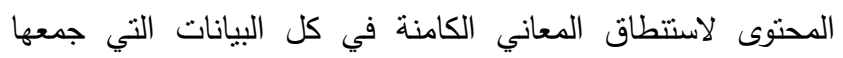

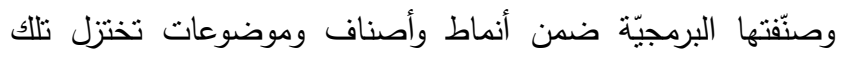
البيانات، والتزم الباحثُ في ذلك تقليبَ النظرِ وإعادَتَهُ استقراءً مدعَّماً بالتفكير الاستتباطيّ، ليصل بها إلى التجريد المطلوب في المعلومات المستخلصة من مضامين البيانات، مما مكّنه من الإجابة عن أسئلة

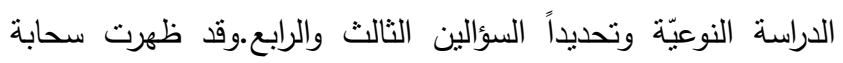

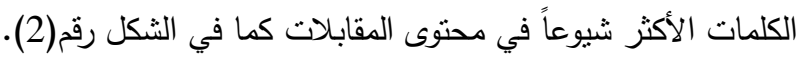

من خلال النظر في الجدول رقم (1) يتبيّن أن درجة موافقة

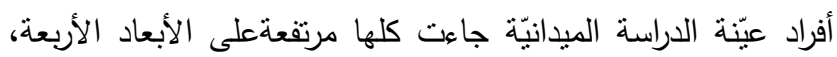

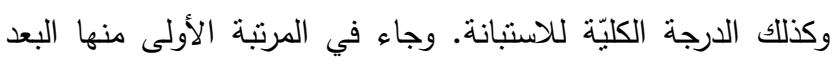

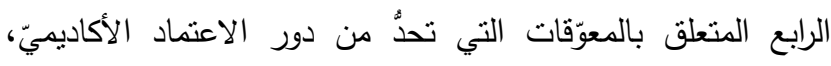

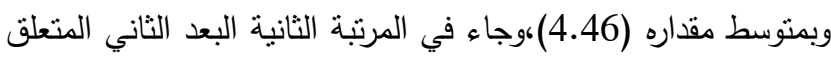

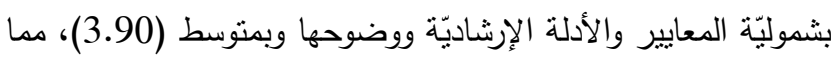

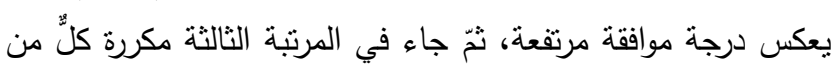

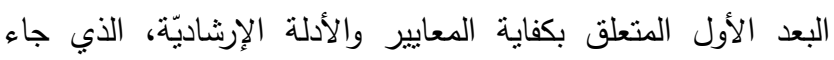

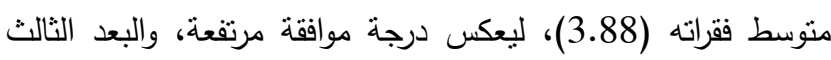

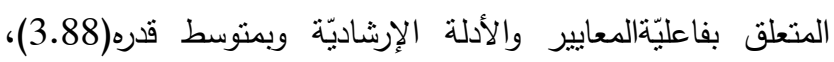
ويعكس أيضا درجة موافقة مرتفعة.وهذه النتائج نوضتح دور الاعتماد

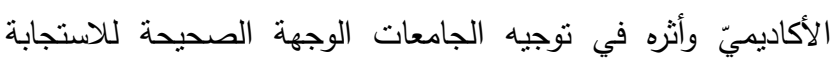

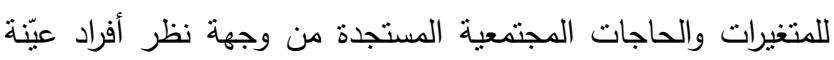

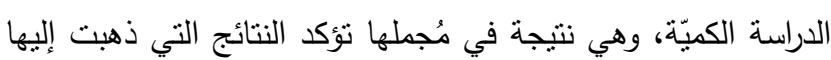

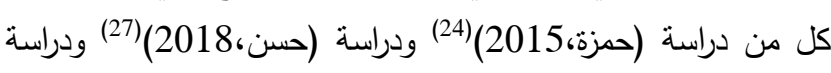

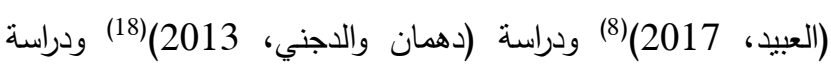
(20)(Elliott \& Goh, 2013)

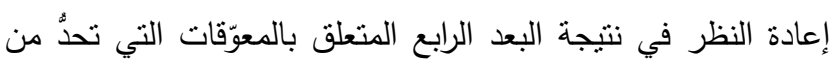

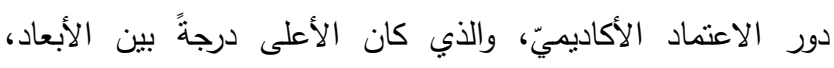

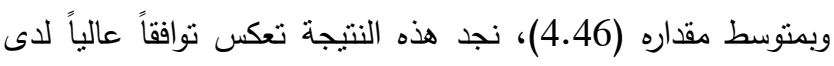

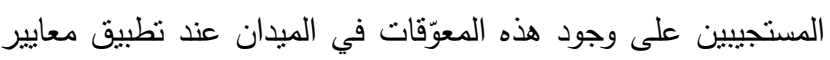

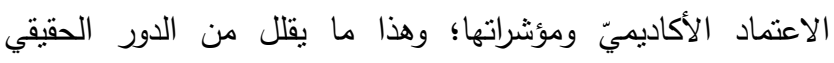

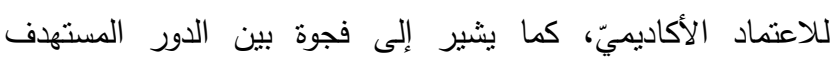

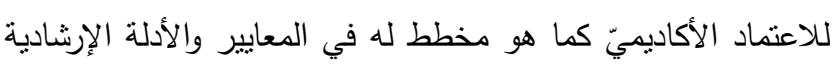
ووثائقها، وبين واقع الحال الملموس كما تظهره الممارسة اليوميّة لعمليات الجودة والاعتماد الأكاديميّ في الجامعات.

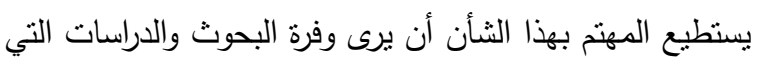

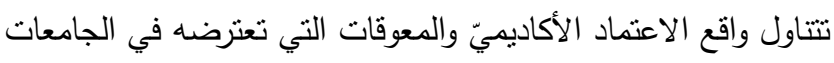

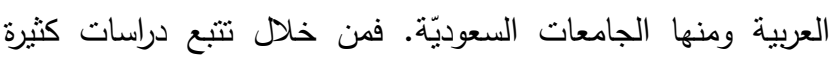
أجريت على الجامعات السعوديّة لتحديد معوّقات تحقيق الجودة لجدية

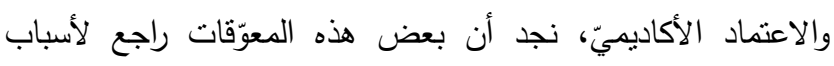


يزيد من أعباء أعضاء هيئة التدريس تجاه جمع الكم الهائل من الوثائق الورقيّة، وقد يقلل هذا الأمر من نركيز عضو هيئة التدريس

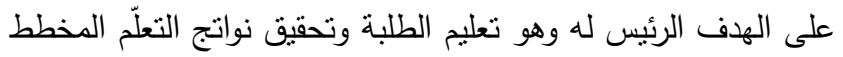

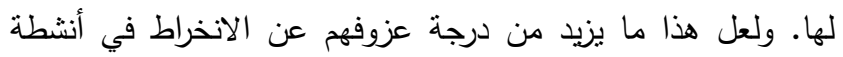

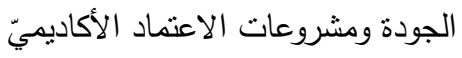
وأما بخصوص نتائج السؤال الثاني من أسئلة المقابلة، المتعلق الإدئ

بشمولية المعايير والمؤشرات والأدلة الإرشاديّة ووضوحها، فيرى لفئري

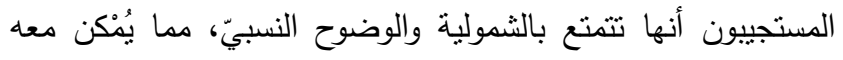
الاعتماد عليها في توجيه نشاطات الجامعات السعوديّة لملاعمة خريجيها لأسواق العمل والحاجات الحقيقية والمستجدة للمجتمعات. وهو ما يلتقي مع ما تفرضه الثثرة الصناعيّة الرابعة على مؤسسات

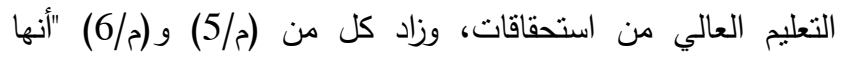

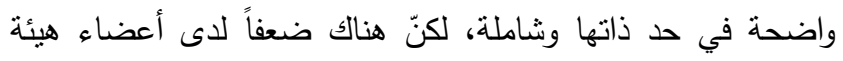

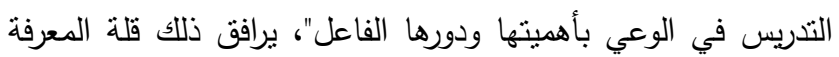
بآليات التعامل معها وتطبيقها، مع قلة المتخصصين في الجودة والاعتماد الأكاديميّ لقيادة هذا الجانب في الأقسام العلميّة. مما يُيرز

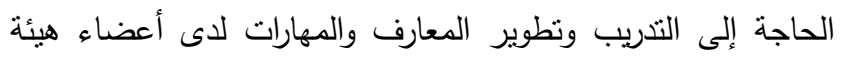
التدريس. وربما كان للتغيير السريع في العاملين في الجودة ولاعتماد الأكاديميّ دور في هذه النتيجة. أما إجابات أفراد المقابلة عن السؤال الثالثة المتعلق بفاعليّة

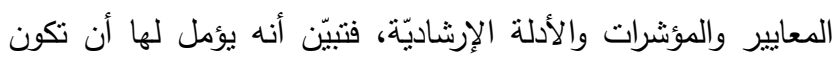

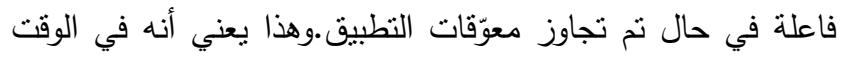

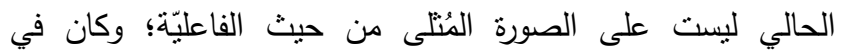
مضامين محتوى المقابلات ما يشير إلى أسباب تنني درجة هذه

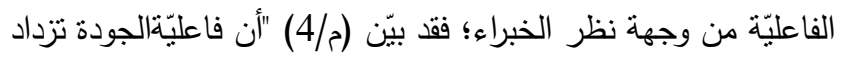

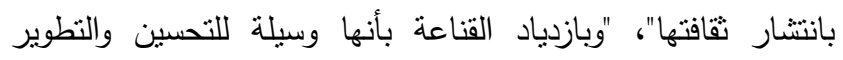

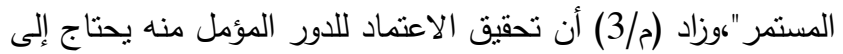
"تذويت ثقافة الجودة وقيمها" في الجامعات لدى الجميع قادةً وعاملين؛ الأمر الذي تشكو منه الجامعات في واقع الحال.

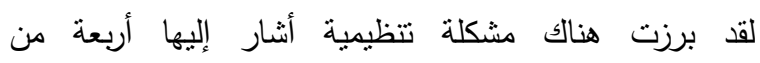

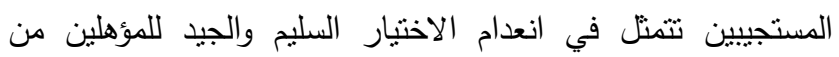
أصحاب الخبرة والتخصص ليقودوا أعمال الجودة ومشروعات الاعتماد الأكاديميّ أسهم في تدني درجة فاعليّة الاعتماد ومعاييره وأدلته

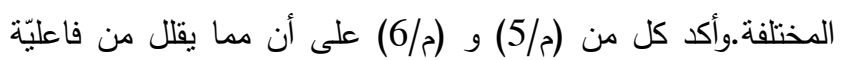

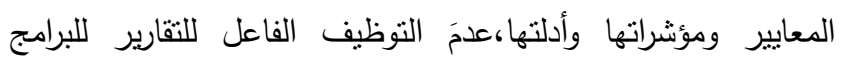
ومقرراتها، وتوصيات اللجان الاستشارية المشتركة مع أرباب العمل،

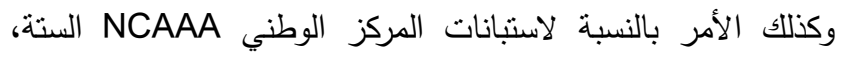

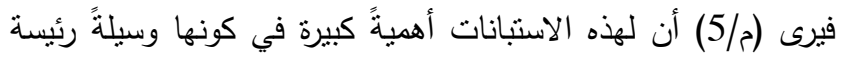

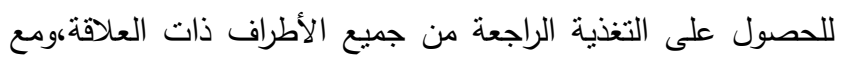

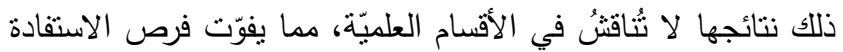
منها في خطط التحسين التي بها تُطلقُ دائرةُ الجودة، وهذه النتيجة

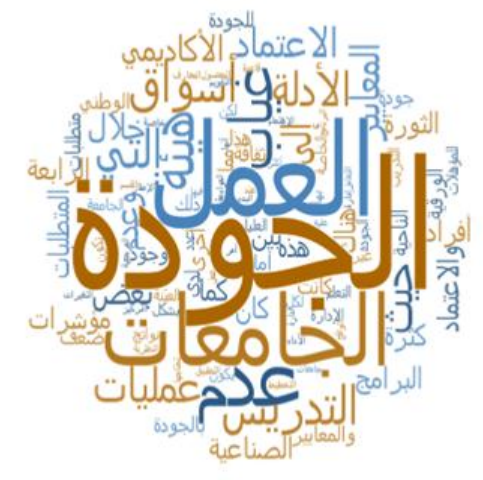

شكل2: سحابة الكلمات Words Cloud الأكثر شيوعاً في نتائج المقابلات مع أفراد عينّة المقابلة المعقّة بحسب برنامج (NVivo)

من خلال النظر في نتائج مقابلة الخبراء حول كفاية معايير

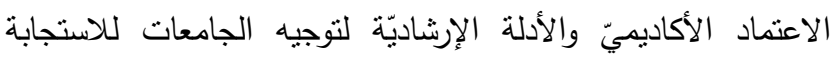

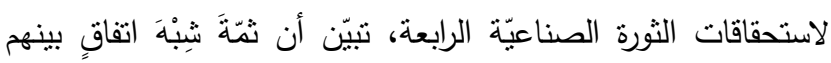

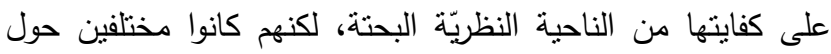

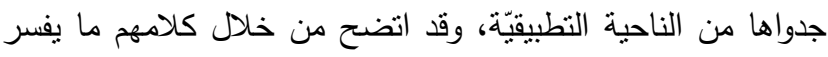

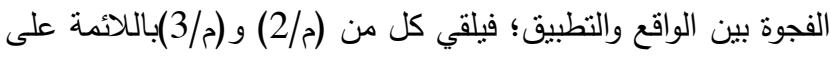

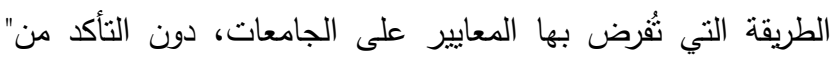

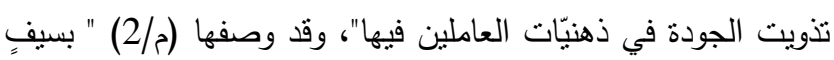

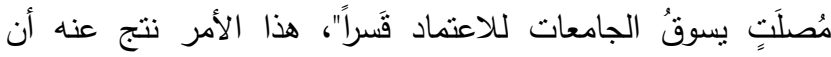

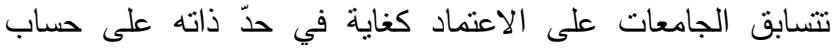

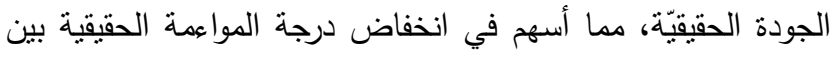

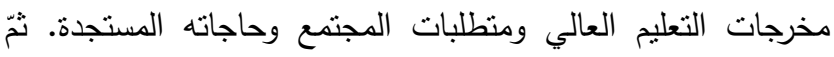
ينساءل (م/2) "هل يعقل أن نتال جامعة ناشئة الاعتماد، ولا نتاله

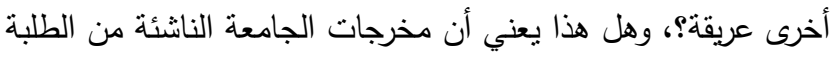

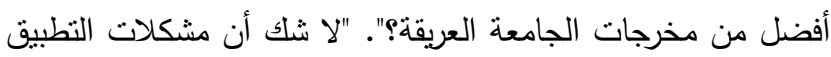
أفرزت مثل هذه النتيجة". لقد بيّن بعض المستجييين أنه يصعب الحكم على المعايير والأدلة بمعزل عن سياقها التطبيقي، الذي يُيرز الكفاية الحقيقة لها، فيرى كل من (م/2) و (م/5) و (م/6) أن آليات تطبيق المعايير والأدلة

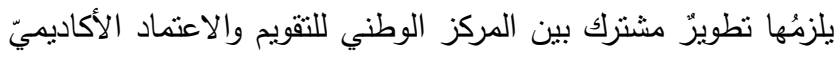

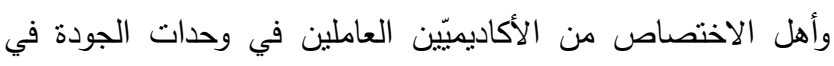

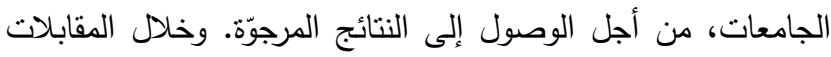
برزت قضية منعلقّة بطبيعة المعايير وحجم منطلبات الوفاء بها، وأنها

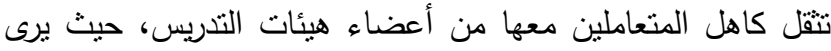

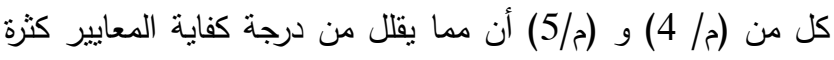

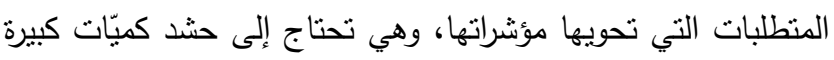
من الأدلة والوثائق، إضافة إلى وقت وجها كبيرين لتجميعها،

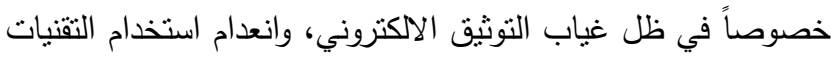
المتقدمة (برمجيّات) في رصد المؤشرات وتوثيق أدلتها. الأمر الذي الذي التئي 
،كافيةٌ من الناحية النظرية لتوجيه الجامعات للاستجابة لاستحقاقات

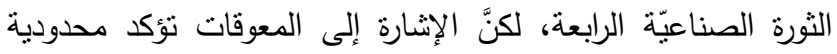

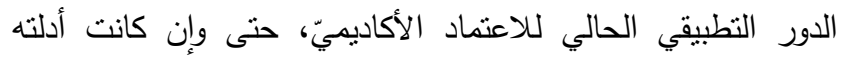

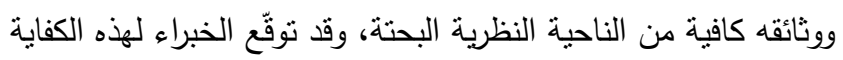

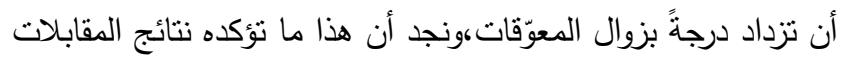

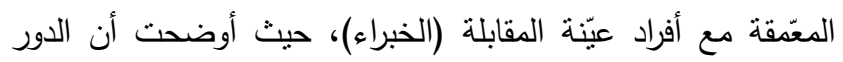

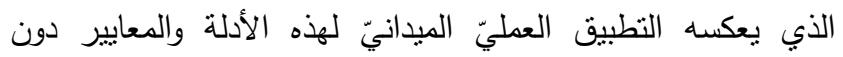

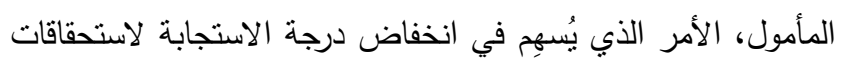

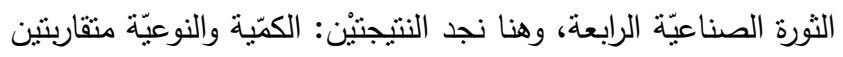
ومتفقتين على كفاية المعايير والأدلة الإرشادية من الناحية النظرية،

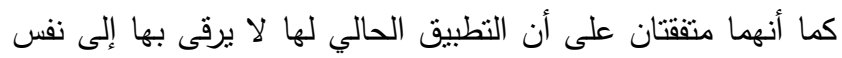

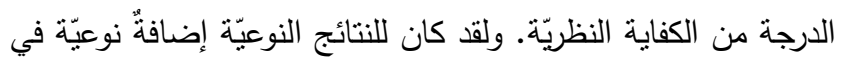

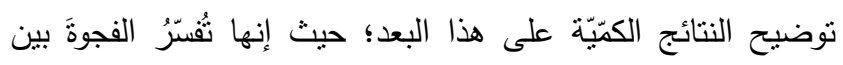

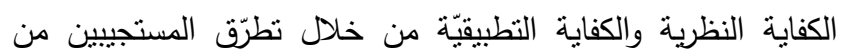
الخبراء لبيانات نوعيّة أكثر عمقاً، كما أضافت النتائج النوعيّة تفصيلاً

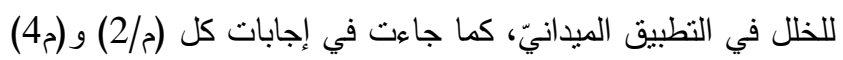
و (م/5) و (م/6).

كما نجد إضافةً خاصة في توضيح النتائج الكمّية على البُعد الثاني المتعلق بشموليّة المعايير والأدلة الإرشاديّة ووضوحها، حيث الثي برى كل من (م/2) (م/4) و (م/5) و (م/6) أنها تتمتع بالثموليّة

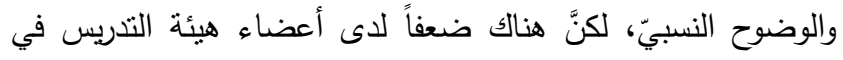

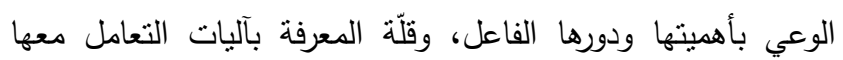

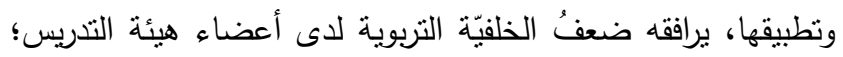

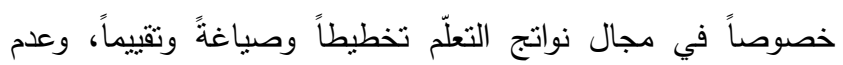

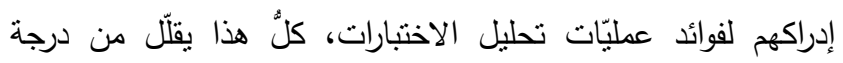

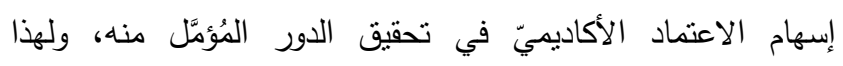

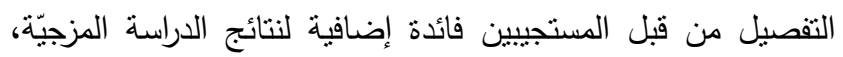

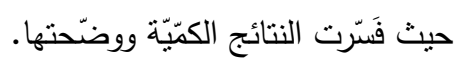

كذلك عند مقارنة النتائج النوعيّة بالنتائج الكميّة المتعلقة بفاعليّة

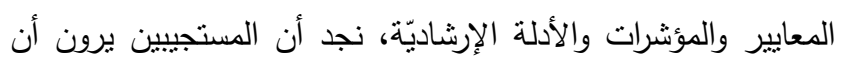
إزالة المعوّقات يزيد من درجة هذه الفاعليّة، ويرون أن الفاعليّة الكاملة

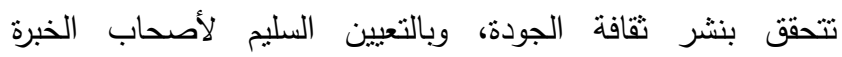

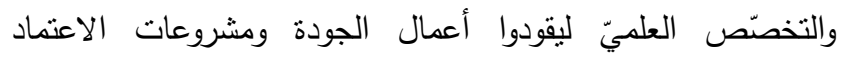

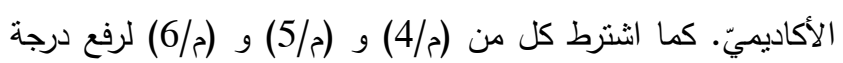

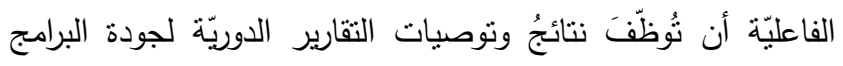
ومقرراتها، وتحليل المؤشرات والاستبانات المختلفة، وتضمين التئن النتائج

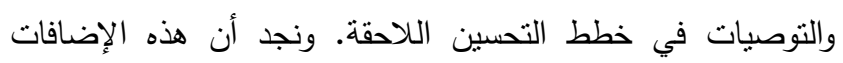
النوّعية تخدم الغرض العام من الدراسة المزجيّة؛ حيث فسّرت النيّة النتائج

الكمّيّة وزادت من نوضيحها.

وأما النتائج المتعلّقة بالمعوّقات التي تؤثر في دور الاعتماد

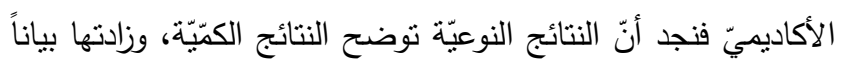

خطيرة من حيث إنها تعكس عدم الجدوى من بعض الممارسات التي

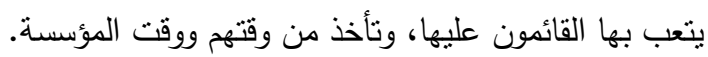

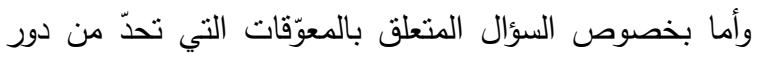

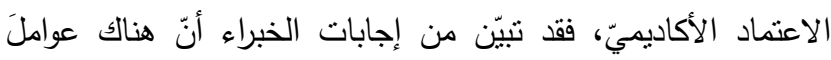

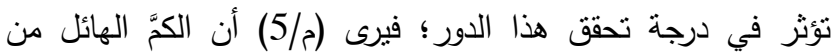

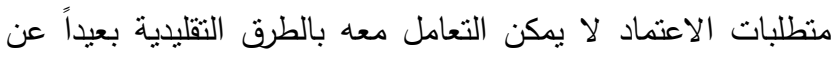
تسخير الثقنيات في الرصد والثوثيق، واستخدام هذه التقنيات في تحليل

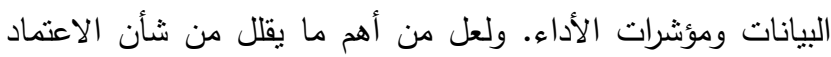

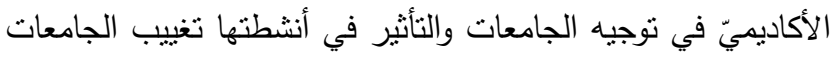

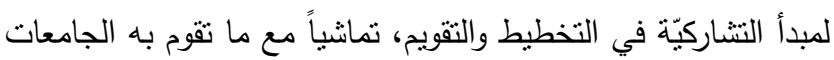
الرائدة على مستوى العالم، حيث يرى (م/6) ضرورة تفعيل التشاركية

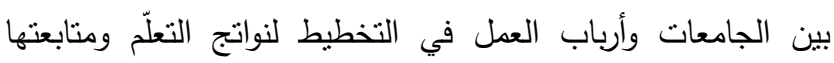
وتقييمها، بما بضمن المواءمة المستمرة لمخرجات الجامعات للحاجات المتجددة للمجتمع وأسواق العمل فيها. ويرى كل من(م/4) و (م/6) أنّ من أهم الأمور المحدّدة لهذا

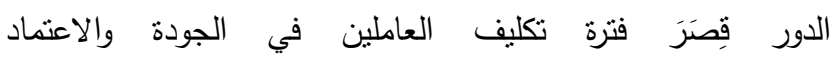
الأكاديميّ،ويقترحان ألا ينم استبدالهم قبل مدّة لا تقل عن 7 سنوات، فئل

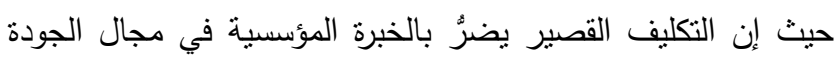

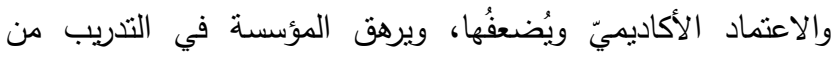

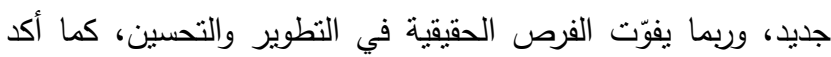

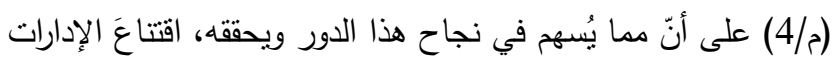

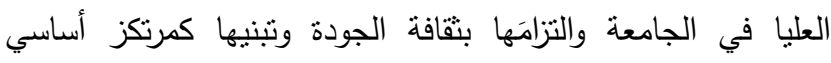

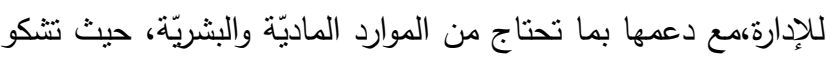

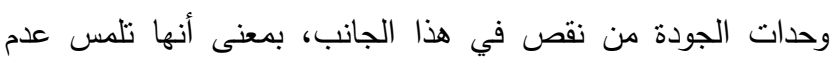

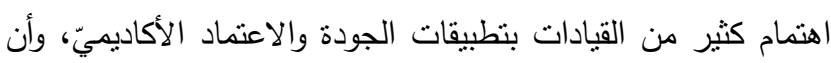
هذه القيادات لا تتبنى الجودة بالمقدار الذي يضمن النتائج المأمولة،

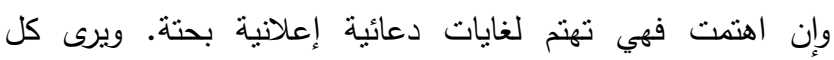

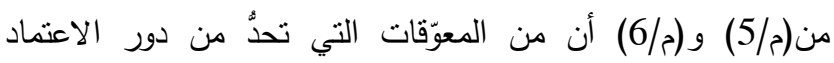

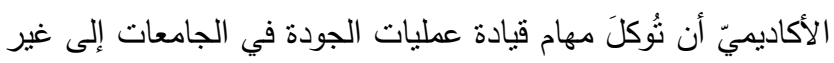

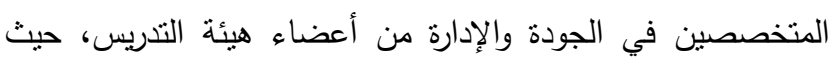
الحاصل فعلياً عدم الاهتمام بهذا المعيار .

إجابة السؤال الرابع: كيف يمكن لنتائج الدراسة النوعيّة أن

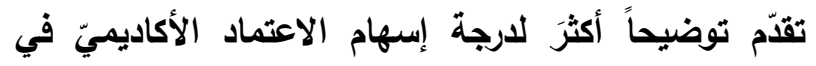

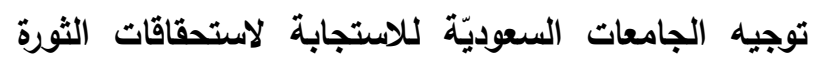
الصناعيّة الرابعة كما قيست كميّاً؟

خُصنص هذا السؤال وإجابته لتفسير النتائج التي تخرج بها

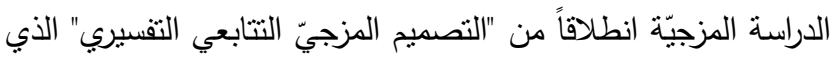

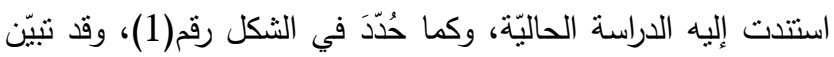

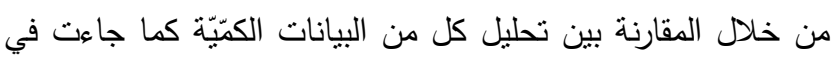

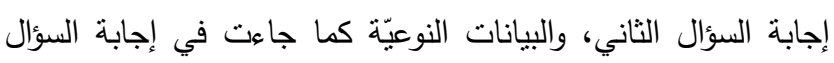

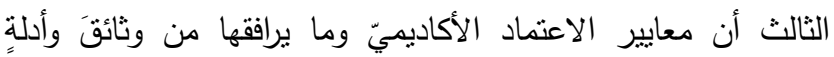


الصعوبة في تتزيله على عالم الواقع Reality World. ويرى الباحث

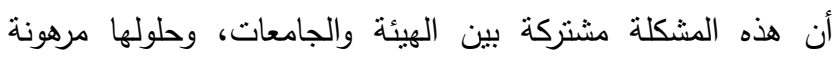
بمقدار ما يكون بين الجهتين من تعاون وتتسيق للاستفادة من التخذية الراجعة بعد كل نطبيق. يرى كرسويل(Creswell)(17) أن المقارنة بين النتائج الكميّة

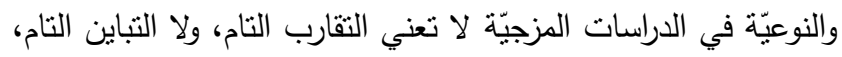
حيث من الممكن أن نوجد بعض الاختلافات بين القليل من المفاهيم

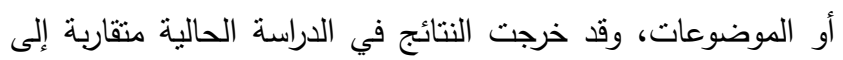

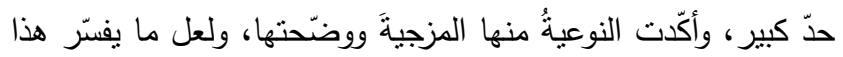
التقارب طبيعة خبرة أفراد العيّنتين؛ حيث إن أفراد عيّنة الدراسة الكيّة الكيّة كانوا من الممارسين لنطبيقات الجودة والاعتماد الأكاديميّ في الميدان،

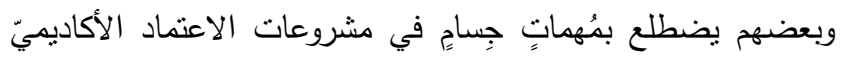

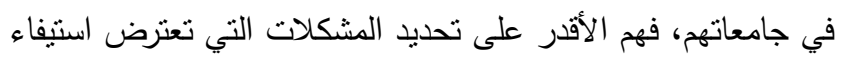

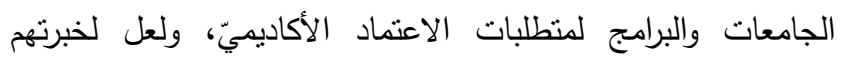

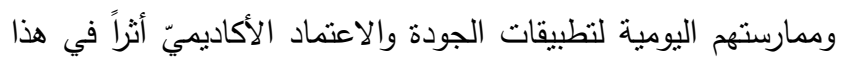
التقدير الدقيق لارجة موافقتهم على فقرات الاستبانة. وكذلك الحال

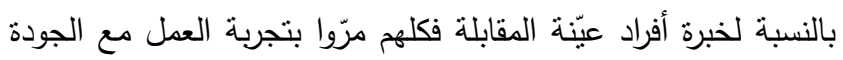

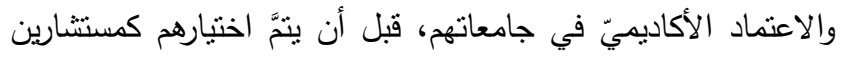

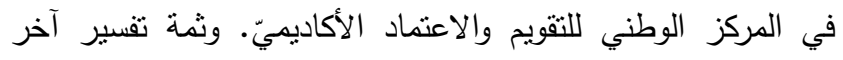

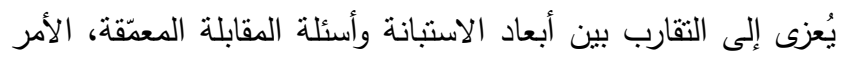

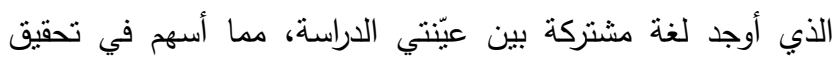
التكامليّة في نتاول أوجه المشكلة والإجابة على تساؤلاتها.

\section{ملخص نتائج الاراسة المزجيّة}

بعد ما سبق من بيانٍ للنتائج وتفسيرها خصنصت الدراسة هذا الجزء منها للخصٍ بالنتائج المزجيّة الآتية ليسهل على القارئ لهان والباحث النظر فيها:

1. بيّتت النتائج كفاية المعايير والأدلة الإرشادية من الناحية

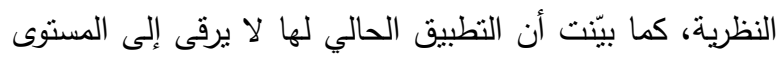

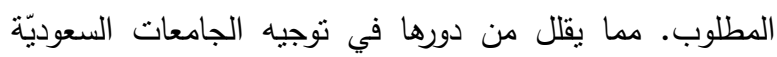
للاستجابة لاستحقاقات الثورة الصناعيّة الرابعة.

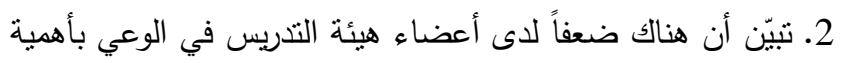

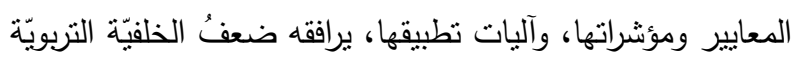
لدى أعضاء هيئة التدريس؛ خصوصاً في مجال نواتج التعلّم

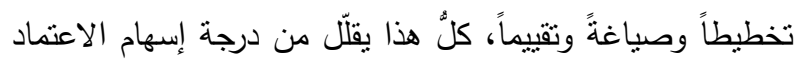

$$
\text { الأكاديميّ في تحقيق الدور المؤمّل منه. }
$$

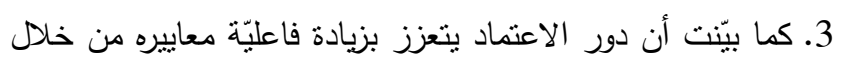

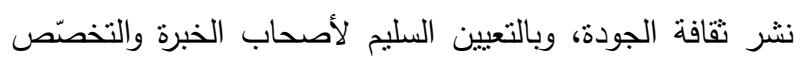
العلميّ ليقودوا أعمال الجودة ومشروعات الاعتماد الأكاديميّ في لئي

$$
\text { الجامعات وكليّاتها وبرامجها. }
$$

4. وضّحت الدراسة أن أهم أسباب الفجوة بين واقع الاعتماد والدور المأمول له وجود معوّقات كثيرة لا بد من تجاوزها وأهمها:
من وجهة نظر الخبراء، وقد تركزت زيادتهم حول: قصر فترة تكليف

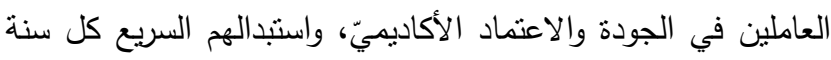

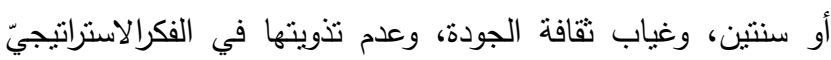
لللمنظمّة وفي ذهنيات العاملين فيها، ثم الحاجة إلى اقتتاع الإدارات

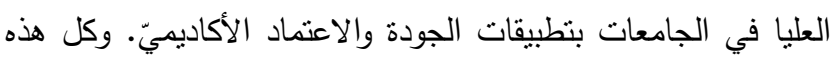

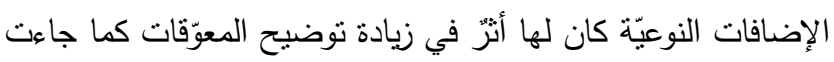

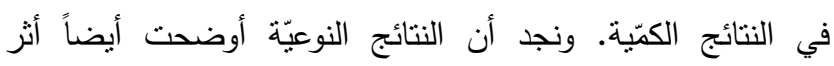

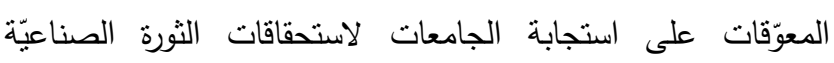
الرابعة، لا بل على أية استجابة للمتغيّرات المتسارعة وما أكثرها.

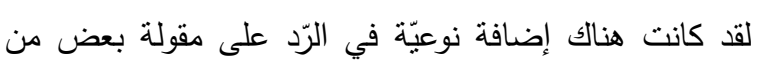

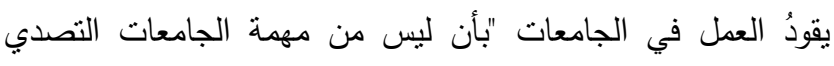

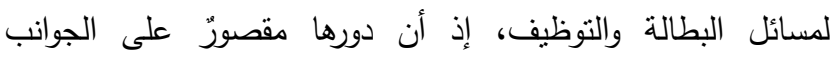

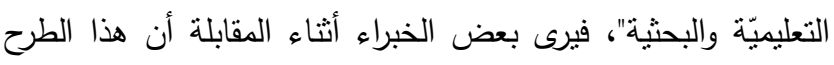

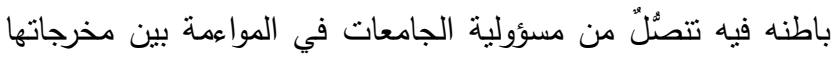

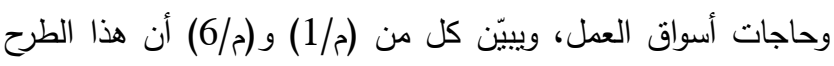

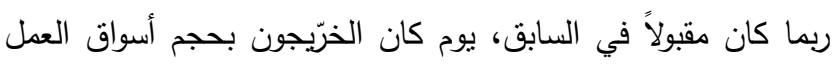

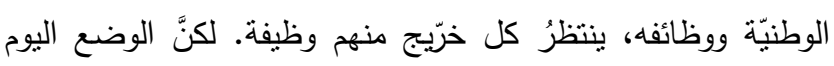

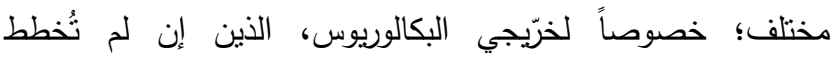

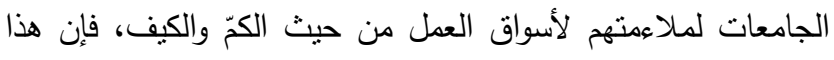

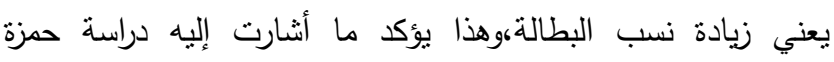

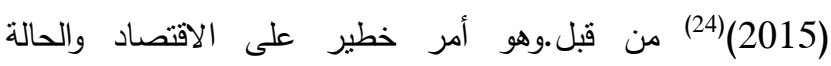

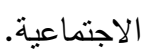

مما سبق ومن خلال النظر في نتائج الدراسة المزجيّة يمكن

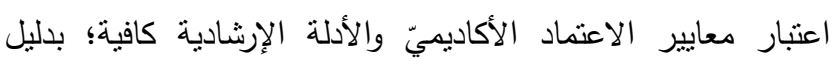

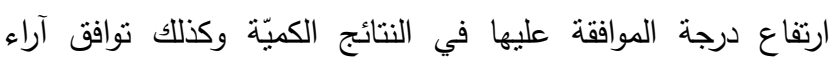

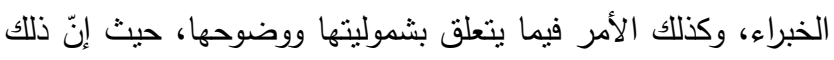
محل اتفاق، لكن الششكلة تبرز عند النطبيق الميداني، وقد كاندان

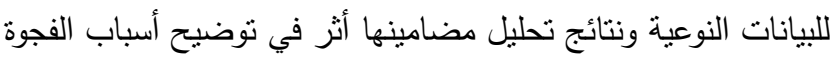

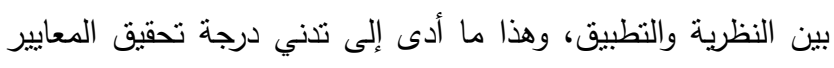

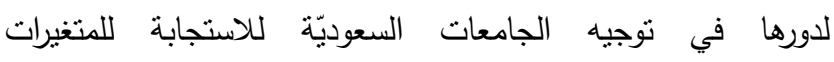
والمستجدات بما فيها استحقاقات الثورة الصناعيّة الرابعة. هذه النتيجة

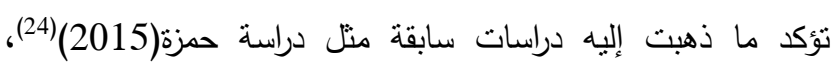

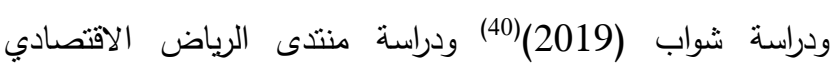

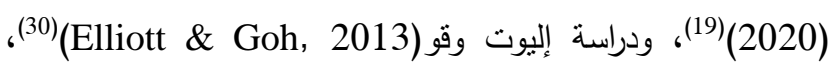

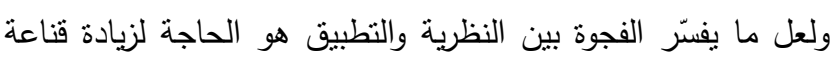

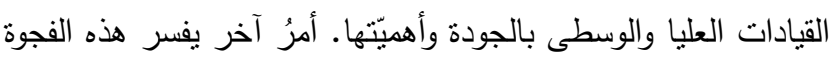

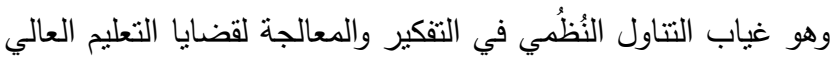

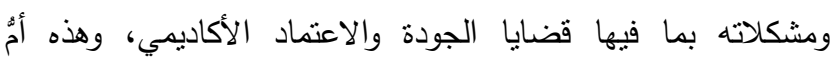

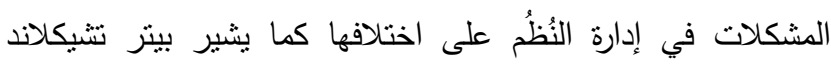
Checkland التجريدي، أو كما سمّاه عالم المفاهيم Conceptual World، لكن فين البحن 
5. على الجامعات تعزيز الثراكات بينها وبين أرباب العمل في القطاعين العام والخاص في التخطيط لنواتج التعلّم وتقييم مؤشراتها.

6. على الجامعات الالتزام بالتدريب التأهيلي والتطويري لأعضاء

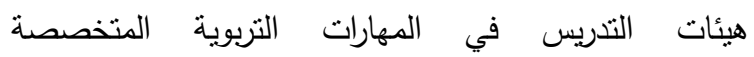

وأهمها:التخطيط لنواتج التعلّم واستراتيجيات تحقيقها وأساليب

قياسها لدى الطلبة، وكذلك التدريب على كيفية الاستفادة من

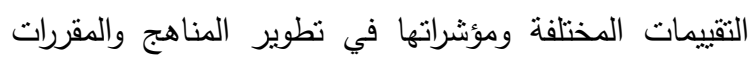

$$
\text { الدراسية. }
$$

\section{References}

1. AHELO. Assessment of Higher Education Learning Outcomes, 2020. Retrieved on 30/5/2020 fromhttps://2u.pw/eX8B0

2. Al-Alami, Fawaz. The Fourth Industrial Revolution, Scientific Record of the International Aspar Forum, November 2017 AD: Creativity and Innovation in the Context of the Knowledge Economy - The Fourth Industrial Revolution, Asbar Center for Studies, Research and Information, pp. 74-78, 2017.

3. Al-Dahshan, Jamal Ali. Academic Accreditation "Foreign Experience and Local Experience", a working paper presented to the second annual conference "Standards for Quality Assurance and Academic Accreditation in Specific Education in Egypt and the Arab World" Faculty of Specific Education - Mansoura University, April 2007.

4. Aldajdaj, Aisha Abdel Fattah Maghawry; Ali, Khalil Mustafa; \& Muhammad Ziauddin Zahir. An evaluation study of university education policy in Egypt from 1982 to the end of the century. The Future of Arab Education: The Arab Center for Education and Development, Vol. 21, No. 90, 357361, 2014

5. Al-Kandari, Nawal Ishaq Ahmed. "Study the relationship between the importance of knowledge of the needs of the labor market and the quality of the outputs of university educational services: an applied study on Kuwait University." Scientific Journal of Economics and Commerce: Ain Shams University - Faculty of Commerce No. 4971 -986, 2010

6. Almaani Aljamie. Arabic dictionaries website. Retrieved 10/5/2020 from https://2u.pw/aI3Ga

7. Almogaddam, Fahd bin Ibrahim. Future skills. Development and evaluation, summary of scientific submissions, International Conference for the Evaluation of Education, Riyadh, 4-6 December 2018.

8. Alobaid, Magda Khalafallah. The role of academic accreditation in controlling the quality of comprehensive quality standards in higher education institutions, Al-Hikma Journal for Media and Communication Studies, No. 11, 2017, pp. 171-191, 2017.

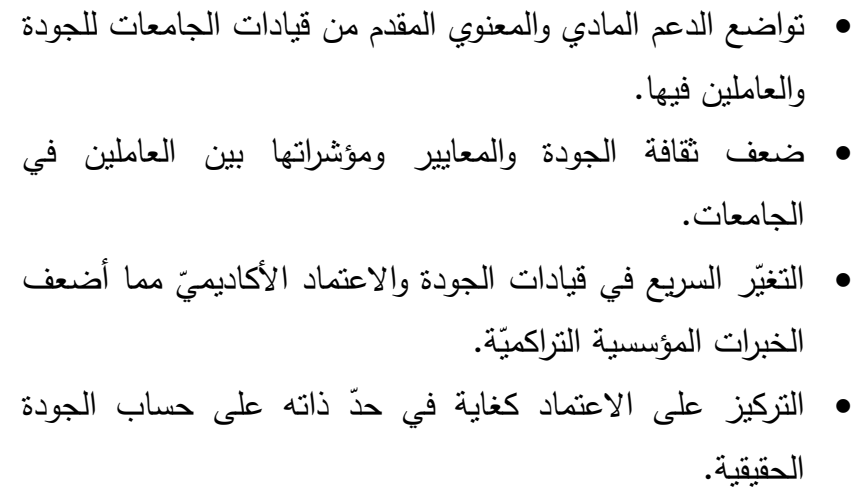

• التغيير الدستمر في وثائق الجودة والاعتماد الأكاديميّ، مما يرهق وحدات الجودة والعاملين فيها عند التعامل معها.

• محدوديّة الثراكات بين الجامعات وأرباب العمل في التخطيط

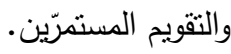

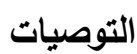

تقدم الدراسة الحاليّة في ضوء نتائجها التوصيات الآتية ليستقيد

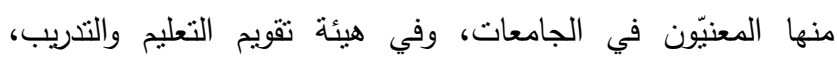
والمركز الوطني للتقويم والاعتماد الأكاديميّ، والعاملون في مجال الجودة والاعتماد الأكاديميّ في الجامعات السعوديّة: 1. أنْ يتبنّى المركز الوطني للتقويم والاعتماد الأكاديميّ شراكةً حقيقيّةً لوضع استراتيجيات تضمن نشر نقافة الجودة والمعايير

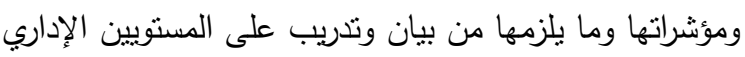

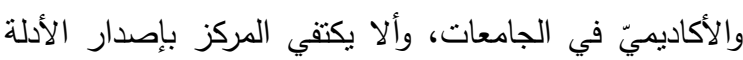
والمعايير منفصلة عن الإسهام في نشر نقافتها.

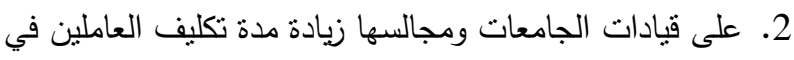

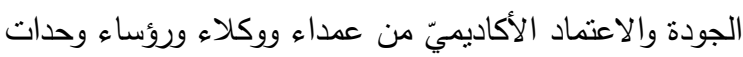

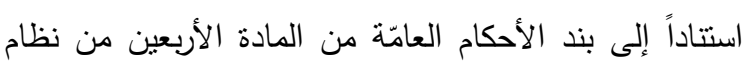

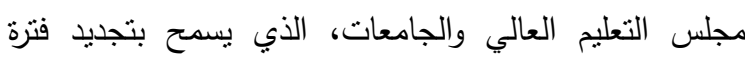

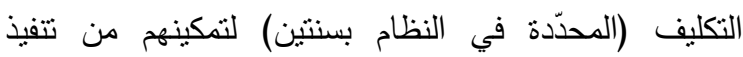
استراتيجيات الجودة والاعتماد الأكاديميّ، لضمان تحقق نتائج يمكن قياسها استتاداً إلى مؤشرات هذه الاستراتيجيات.

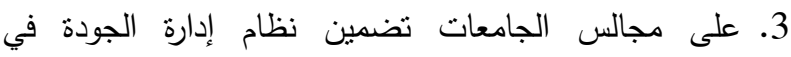

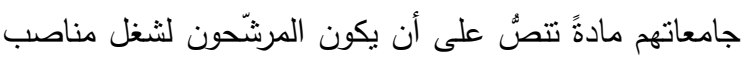

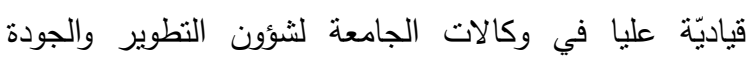

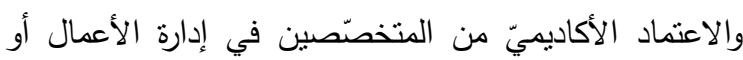

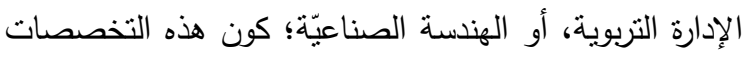

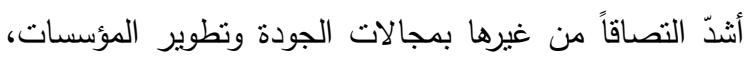
وأصحابها يتقنون التعامل مع مؤشرات الأداء تخطيطاً ومتابعةً

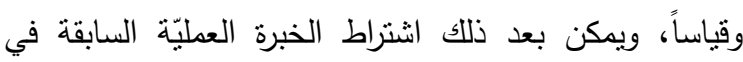

$$
\text { وحدات الجودة في الكليّات أو الأقسام العلميّة. }
$$

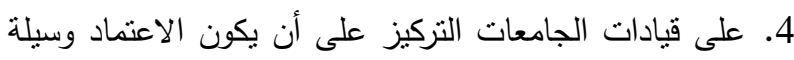

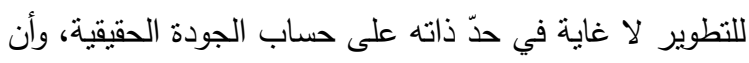
يكون ذللك ضمن استراتيجيات الجامعة المعلنة. 
22. Frey, Carl Benedikt \& Osborne, Michael A. the Future of Employment: How Susceptible Are Jobs to Computerization, 2013. Retrieved on 13/2/2020 from: http://cutt.us/uGaaI

23. Gibbs, Graham. (2007). Analyzing Qualitative Data, the SAGE Qualitative Research Kit. SAGE Publications

24.Hamza, Ahmed Mohamed Abdel Karim. Aligning the outcomes of Saudi universities with the needs of the labor market: a future vision for Saudi universities. Journal of Psychological Counseling, Ain Shams University, No. 42, 365-391, 2015

25. Harden, R.M. Outcome-based education - the ostrich, the peacock and the beaver. Medical Teacher 29: 666-671, 2007.

26. Harvard Business Review. (2020). Administrative concepts, the definition of the fourth industrial revolution. Retrieved on 20/26/2020 from https://cutt.us/v8D9U

27. Hasan, Shefaa Blasem. The Impact of Academic Accreditation on Meeting the Needs of the Labor Market - An Analytical Exploratory Research for Specific Views of Teachers at the Administrative Technical College / Baghdad. Journal of Administration and Economics, forty-first year 105, 68-87, 2018

28. Heathway, Larry. Mastery of the Fourth Industrial Revolution, Fikr Magazine, Obeikan Center for Research and Publishing, No. 4, 11213, 2016.

29. Holtel, Stevan. Artificial Intelligence Creates a Wicked Problem for the Enterprise, Procedia Computer Science, 99, 171-180, 2016.

30. Hussein, Salamah Abdul Azim. Quality assurance and accreditationineducation. Riyadh: Alsoultiah Educational House, 2005

31. Lenn, Marjorie Peace Global Trends in Quality Assurance in Higher Education, World Education News \& Reviews, v. 5, no. 2, , pages $1-21,1992$

32. Lueger, M. \& Vettori, O. (2007): Finding the right measure? An interactionist view on quality cultures and the role of quality measurement. Paper presented at the 8th, Biennial Conference of the International Network of Quality Assurance Agencies in Higher Education, Toronto, Canada, 2-5 April 2007

33. OECD. The Organization for Economic Cooperation and Development. Testing student and university performance globally, 2008. Retrieved on 12/5/2020 from https://2u.pw/VNh7c

34. OECD. The Organization for Economic Cooperation and Development. Survey of Adult Skills (PIAAC), 2011. Retrieved on, 12/5/2020 from http://www.oecd.org/skills/piaac/

35. Penprase. B. E. the Fourth Industrial Revolution and Higher Education. In: Gleason N. (eds) Higher Education in the Era of the Fourth Industrial Revolution. Palgrave Macmillan, Singapore, 2018.
9. Alshehri, Wafa; Al-Saadoun, Batoul Abdel Aziz. The reality of the relationship between the Fourth Industrial Revolution and education outcomes from the viewpoint of faculty members at the General Organization for Technical and Vocational Training in Al-Kharj city, the scientific journal of the Faculty of Education at Assiut University, vol. 35, p. 11, 484-524, 2019.

10. Angel-Urdinola, Diego F., Semlali, Amina, and Brodmann1, Stefanie. Non-Public Provision of Active Labor Market Programs in ArabMediterranean Countries: An Inventory of Youth Programs. 10.The World Bank, 2010. Retrieved on 25/5/2020 from https://cutt.us/YNIL3

11. Ayrout, Mustafa Muhammad Mustafa, and Heba Ibrahim Abdullah Hammad. "The suitability of the specializations offered by public Jordanian universities to meet the needs of the public sector." Educational and psychological studies: Zagazig University - Faculty of Education p. 100, 139 - 159, 2018.

12. Bahzad, Ali Abdullah. "The states of cooperation enter the fourth industrial revolution with care: technical policies, e-government, and fiber-optic cities." Industrial Cooperation in the Arab Gulf: Gulf Organization for Industrial Consulting, No. 117, 18-19, 2017.

13. Blouw, Max. Universities should educate employers should train, 2013. Retrieved on 12/5/2020 from https://2u.pw/cxT5a

14. Cambridge Dictionary. 2020. Retrieved on 16/5/2020 fromhttps://dictionary.cambridge.org//

15. CEDA. Australia's future workforce? The Committee for Economic Development of Australia. Retrieved on 16/5/2020 from https://cutt.us/yDST1

16. Checkland P.. Soft Systems Methodology in action.1999, John Wiley \& Sons Ltd.: Hoboken.

17. Creswell, John W. Research Design: Qualitative, Quantitative, and Mixed Methods 4th ed. 2014. SAGE Publications, Inc.

18. Dahman, Maryam Mahmoud; Dojani, Iyad Ali. The role of external evaluation in developing the performance of education colleges in Palestinian universities in Gaza Governorate and ways to activate it. Unpublished Master Thesis, Islamic University (Gaza), Occupied Palestine, 2013.

19. Davis, Nicholas. What is the fourth industrial revolution?, 2016. Retrieved on 2/6/2020 from https://2u.pw/mFHka

20. Elliott, Catherine \& Goh, Swee C. Does accreditation promote organizational learning? A multiple case study of Canadian university business schools Journal of Management Development 32(7), 736-755, 2013 .

21. ETS. Educational Testing Service, The Organization for Economic Co-operation and Development, 2020. Retrieved on 26/5/2020 from https://www.ets.org/ 
36. PISA. Program for International Student Assessment, 2020. Retrieved on 30/5/2020 fromhttp://www.oecd.org/pisa/

37. Pompa, C. Jobs for the Future, London: Overseas Development Institute (ODI). 2015

38. Riyadh Economic Forum. (2020). Ninth session studies, future jobs in Saudi Arabia. Retrieved 4/20/2020 from https://cutt.us/uOaMp

39. SAGE. Journal of Mixed Methods Research, 2020. Retrieved on 15/6/2020 from https://2u.pw/mN8W9

40. Schwab, Klaus. "The Formation of the Fourth Industrial Revolution." Fikr Magazine: The Obeikan Research and Publishing Center G25 (2019): 138 - 139, 2019.

41. Schwab, Klaus. (2016). The Fourth Industrial Revolution: what it means, how to respond, retrieved on 10/7/2020 from https://2u.pw/kAKqh

42. Tashakkori, Abbas \& Teddlie, Charles. SAGE Handbook of Mixed Methods in Social \& Behavioral Research, 2 ed, 2010. Retrieved on 15/6/2020 from https://2u.pw/vILsY

43. Tawfeq, Mohamed Hassan. "The Fourth Industrial Revolution, and the challenges of sustainable development", Proceedings of the fourth episode of the 2018-2019 expert meeting, National Planning Institute, Egypt 2019.

44. Thompson, Mark. How do Saudi youth view future job skills? Special report, King Faisal Center for Research and Islamic Studies. Retrieved on 1/2/2020 from: https://cutt.us/sJn8Q

45. Vasvikis, Elias. The Fourth Industrial Revolution ... an ally or an enemy of jobs? Echo Human Resources Magazine, Federal Authority for Government Human Resources, Abu Dhabi, $p$ 10.6-15, 2019.

46. World economic forum. Insight Report: Towards a Reskilling Revolution, A Future of Jobs for All, World Economic Form In collaboration with The Boston Consulting Group, January 2018.Retrieved on $2 / 2 / 2020$ from: http://cutt.us/pyqLB

47. World Economic Forum. The Future of Jobs: Employment, Skills and Workforce Strategy for the Fourth Industrial Revolution, 2016.Retrieved on $1 / 6 / 2020$ from https://2u.pw/gakPv. 